\title{
The Influence of Water and Solvent Uptake on Functional Properties of Shape-Memory Polymers
}

\author{
Ehsan Ghobadi $\left(\mathbb{D},{ }^{1}\right.$ Axel Marquardt, ${ }^{2}$ Elias Mahmoudinezhad Zirdehi $\left(\mathbb{D},{ }^{3}\right.$ Klaus Neuking, \\ Fathollah Varnik, ${ }^{3}$ Gunther Eggeler, ${ }^{2}$ and Holger Steeb $\mathbb{D D}^{1,4}$
}

${ }^{1}$ Institute of Applied Mechanics (CE), University of Stuttgart, Stuttgart, Germany

${ }^{2}$ Institute for Materials, Ruhr-University Bochum, Bochum, Germany

${ }^{3}$ ICAMS, Ruhr-University Bochum, Bochum, Germany

${ }^{4}$ SimTech, University of Stuttgart, Stuttgart, Germany

Correspondence should be addressed to Ehsan Ghobadi; ehsan.ghobadi@mechbau.uni-stuttgart.de

Received 28 December 2017; Revised 8 April 2018; Accepted 8 May 2018; Published 28 May 2018

Academic Editor: Gianluca Rizzello

Copyright ( $\odot 2018$ Ehsan Ghobadi et al. This is an open access article distributed under the Creative Commons Attribution License, which permits unrestricted use, distribution, and reproduction in any medium, provided the original work is properly cited.

In this contribution, diffusion of water, acetone, and ethanol into a polymer matrix has been studied experimentally and numerically by finite element approaches. Moreover, the present study reports an assessment of different thermomechanical conditions of the shape-memory (SM) performance, for example, stress- or strain-holding times in stress- or strain-controlled thermomechanical cycles and the effect of maximum strain. According to the results presented here, the uptake of acetone in Estane is much higher than ethanol and follows classical Fickian diffusion. Further, a series of thermomechanical measurements conducted on dry and physically (hydrolytically) aged polyether urethanes revealed that incorporation of water seems to have an appreciable impact on the shape recovery ratios which can be attributed to the additional physical crosslinks. However, no obvious difference in shape fixation of dry and physically (hydrolytically) aged samples could be recognized. Furthermore, by decreasing the strain-holding time, shape recovery improves significantly. Moreover, the shape fixity is found to be independent of holding time. The shape recovery ratio decreased dramatically with an increase in the stress-holding time.

\section{Introduction}

The thermally induced shape-memory effect (SME) of a system is an ability to maintain a temporarily fixed deformation that is established after the application of a specific thermomechanical treatment called programming [1]. Such programmed polymers can shift back to their original shape, when exposed to heat and pass a certain temperature called transition temperature $\left(\theta_{\mathrm{sw}}\right)$ [1]. The temperature $\theta_{\mathrm{sw}}$ is related to the thermal transition of switching domains and can be the glass $\left(\theta_{\mathrm{g}}\right)$ or the melting temperature $\left(\theta_{\mathrm{m}}\right)$ [2]. Such programming procedure consists of three steps: (I) heating and deforming above $\theta_{\text {sw }}$, (II) cooling to $\theta<\theta_{\text {sw }}$ to solidify the switching domains, and (III) unloading at this temperature to obtain a programmed fixed shape [3].
The recovery of a SMP is performed by entropy acquirement of switching domains, when moving from an oriented (programmed) configuration to a random coil (recovered) chain conformation by heating to $\theta>\theta_{\mathrm{sW}}$ [4].

Functional properties of SMPs are normally studied by cyclic thermomechanical tests $[5,6]$. Characteristic functional properties for the quantification of the SME are the shape fixity ratio $\left(R_{\mathrm{f}}\right)$ and the shape recovery ratio $\left(R_{\mathrm{r}}\right) . R_{\mathrm{f}}$ describes the capability of a polymer to temporarily fix an applied deformation, whereas $R_{\mathrm{r}}$ expresses how well the original shape is recovered.

Several parameters can alter the functional properties of polymers. Among them are, for example, the maximum strains during programming or the holding time after deformation. It was observed that the functional properties 
of thermally induced SMPs can also be significantly affected or even triggered by the uptake of solvents [7-10]. This can lead to chemical or physical aging [11-13]. Influencing the functional properties of SMPs through chemical aging is irreversible. In such processes, the chemical structure of the system is irreversibly changed, for example, in hydrolytically degraded polymers $[13,14]$. In contrast, physical aging occurs when the molecular structure of the polymer does not change. Physical aging is reversible, so that the physically aged sample can be brought back to its initial state with some measures, for example, heating and drying [15].

The shape-memory capability of a system in vicinity to humidity or solvents can be strongly changed, before, during, and after programming [16, 17]. For instance, the worsening of shape recovery of a programmed polymer is an effect of physical aging because of humidity uptake which starts right after the first day of keeping them at a temperature lower than their glass transition temperature $\left(\theta_{\mathrm{g}}\right)$ that may cause an incomplete, premature loss of the programmed shape [18]. This is the main reason why SMPs have a certain lifetime and have to be stored and maintained under particular conditions [19].

The observation that humidity can substantially influence the functional properties of SMPs has gained abundant attraction in recent years and is of great relevance for numerous medical applications $[20,21]$. This has motivated the development of moisture-triggered SME [16-18]. The fundamental mechanisms of moisture triggering are either destabilization and elimination of hydrogen bonds [9], water-induced dissolution of crystalline domains [22], or degradation of switching domains responsible for shape fixation and recoiling of the chain segments during recovery [7].

Although accidental life-altering processes of polymers through physical or chemical aging are not prepossessing and desirable, targeted aging of materials before practical applications is required. Therefore, one important question is how functional properties of a SMP change, if it is "meaningfully" and "targeted" aged before programming (e.g., by introducing solvent molecules into the polymer matrix)? To our best knowledge, there is no systematic research to answer this question. Therefore, the aim of this study is to explore, whether targeted physical aging "prior to programming" can influence the functional properties of a commercially available polyether urethane (Estane, Lubrizol, Ovele Westerlo, Belgium). For this reason, dry and physically aged samples have been prepared. Physical aging was performed through the uptake of three different solvents: acetone $\left(\mathrm{C}_{3} \mathrm{H}_{6} \mathrm{O}\right)$, ethanol $\left(\mathrm{C}_{2} \mathrm{H}_{6} \mathrm{O}\right)$, and water $\left(\mathrm{H}_{2} \mathrm{O}\right)$, and their sample-specific transport behavior was numerically studied. Moreover, the related changes in $\theta_{\mathrm{g}}$ were discussed experimentally and numerically by molecular dynamics (MD) simulations.

It was observed that the incorporation of the abovementioned solvents into the polymer matrices significantly changed the shape-memory capability of Estane. However, in the present contribution, only the results for hydrolytically (physically) aged samples will be discussed. This is because of the fact that the amount of diffused acetone and ethanol in the polymer samples at the single steps of the shapememory cycle could not be controlled, so that at the end of experiments unpredicted desorption effects have been observed and the data were not reproducible. For waterswollen samples, on the other hand, no significant mass change was detected.

Following the previous studies with Estane [23] and experimental water sorption investigations performed here, a maximum mass gain of $3 \mathrm{wt} . \%$ to $3.1 \mathrm{wt} . \%$ can be expected.

For the quantification of functional properties of Estane, cyclic thermomechanical tests consisting of two subsequent cycles with a uniaxial strain of $\varepsilon_{\mathrm{m}}=10 \%$ was applied for dry and hydrolytically aged samples. Additionally, the same procedure was repeated with different holding times and with different maximum strains of $\varepsilon_{\mathrm{m}}=30 \%, 60 \%, 100 \%$, and $150 \%$ for both dry and hydrolytically aged samples.

\section{Materials and Methods}

2.1. Materials. In the present contribution, aliphatic SMpolyurethane Estane (designation: ETE75DT3 NAT022) granulates (Lubrizol, Ovele Westerlo, Belgium) have been processed using an injection molding machine (Arburg Allrounder 270M 500-210, Lossburg, Germany). Processing steps and detailed sample preparation stages have been explained in [24, 25]. Molecular weight and weight distribution of Estane have been determined by Gel permeation chromatography, and results can be found in Supplement I. Fig. S1 shows size-exclusion gel permeation chromatography analysis of Estane. Here, an average molecular weight of $126 \mathrm{~kg} /$ mole was determined.

For solvent uptake and physical aging operations, three different solvents have been used: deionized water $\mathrm{H}_{2} \mathrm{O}$ (HPLC grade, VWR Chemicals, Darmstadt, Germany), ethanol $\mathrm{C}_{2} \mathrm{H}_{6} \mathrm{O}$ (analytical reagent grade, absolute $99.8+\%$, certificated for analysis, Fisher Scientific UK), and acetone $\mathrm{C}_{3} \mathrm{H}_{6} \mathrm{O}$ (analytical reagent grade, certificated for analysis, Fisher Scientific UK).

2.2. Numerical Investigations. Numerical investigations of Fickian diffusion have been studied with the commercial Finite Element software package COMSOL 5.0 Multiphysics.

Modeling the $\theta_{\mathrm{g}}$ of dry and physically (hydrolytically) aged polymer samples has been performed through MD simulations with the MD software package LAMMPS, developed at Sandia National Laboratories [26]. Here, a generic model of a polymer with a finite extensible nonlinear elastic (FENE) potential has been employed, which allows to focus on generic rather than material-specific aspects. All simulations were performed in an NPT (number of molecules, pressure, and temperature constant) ensemble using Nose-Hoover thermostat and barostat to apply desired temperature and pressure. The equations of motions are integrated with the velocity Verlet algorithm.

The presented atomistic model is built up of 156 chains of 64-bead length, along with various numbers of small particles. The nonbonded interactions are modeled by the Lennard-Jones (LJ) potential $U_{\alpha \beta}{ }^{\mathrm{LJ}}$, and the connectivity of 


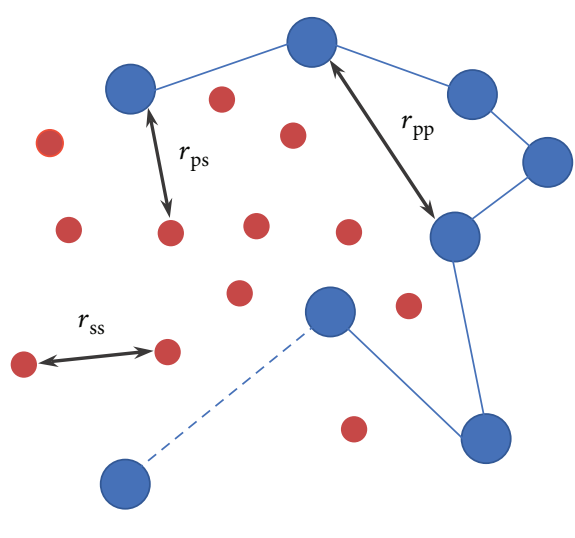

(a)

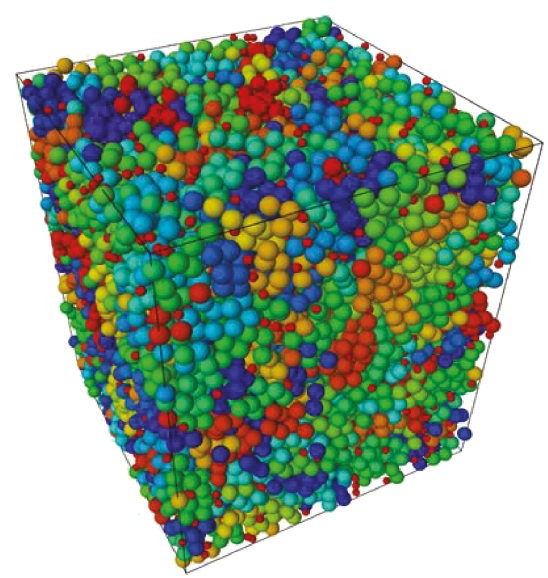

(b)

FIgure 1: (a) A schematic view of the model used in the MD simulations. (b) A snapshot of the simulation box containing polymers and small molecules. Different chains are shown with different colors to improve visibility. Small molecules appear as small red spherical particles.

covalent bonds along the chains is ensured via the FENE potential $U_{\mathrm{FENE}}$ as follows:

$$
\begin{aligned}
U_{\mathrm{FENE}} & =-\frac{1}{2} K R_{0}^{2}\left[\ln \left(1-\left(\frac{r}{R_{0}}\right)^{2}\right)\right], \\
U_{\alpha \beta}^{\mathrm{LJ}} & =4 \epsilon_{\alpha \beta}\left[\left(\frac{\sigma_{\alpha \beta}}{r_{\alpha \beta}}\right)^{12}-\left(\frac{\sigma_{\alpha \beta}}{r_{\alpha \beta}}\right)^{6}\right],
\end{aligned}
$$

where $\epsilon_{\alpha \beta}, \sigma_{\alpha \beta}, r_{\alpha \beta}, k=30 \epsilon_{\mathrm{pp}} / \sigma_{\mathrm{pp}}^{2}, r$, and $R_{0}=1.5 \sigma_{\mathrm{pp}}$ are the van der Waals (vdW) potential strength, the distance with zero potential energy, interatomic distance, strength factor of bonded potential, covalent bond length, and the breaking limit of the bonds, respectively. It should be noted that $\alpha, \beta \in\{\mathrm{p}, \mathrm{s}\}$ and $\mathrm{p}$ and $\mathrm{s}$ stand for polymer and small molecules (solvents), respectively. The quantity $\sigma_{\mathrm{pp}}$ is chosen to equal to 1 , and the size of small particles is adjusted by setting $\sigma_{\mathrm{ss}}=0.5 \sigma_{\mathrm{pp}}$. The quantity $\sigma_{p s}$ is obtained by the arithmetic mean of $\sigma_{\mathrm{pp}}$ and $\sigma_{\mathrm{ss}}$.

Figure 1(a) shows a schematic view of the chain segment of the polymer in the vicinity of solvent molecules. As depicted in this picture, the distances between atoms of polymers and solvents are represented with $r_{\mathrm{pp}}, r_{\mathrm{sp}}$, and $r_{\mathrm{ss}}$, where $r_{\mathrm{pp}}$ is the distance between atoms of polymers, $r_{\mathrm{ps}}$ between atoms of polymers and solvents, and $r_{\mathrm{ss}}$ between atoms of solvents, respectively. Moreover, in Figure 1(b), a snapshot of the simulation box is also shown. For the construction of initial polymer chains, the monomers are placed regularly on a $3 \mathrm{D}$ grid after which the system is melted at a relatively high temperature of $\theta=2\left(\theta_{\mathrm{g}}=0.44\right.$ for the present model and all quantities in LJ units) to achieve statistically random distributions of chain conformations. It should be noted that for the sake of data interpretation, three independent packing models were built and simulations were performed for all three samples. The results shown here are an average out of three.
2.3. Experimental Sorption and Diffusion Studies. Prior to any experiment, the injection-molded plates of Estane with a thickness $2 \mathrm{~mm}$ have been kept in a vacuum desiccator to keep them dry. Afterwards, the plates were cut to round discs of diameter $44.5 \mathrm{~mm}$ with a mass of $3.777 \pm 0.017 \mathrm{~g}$. For sorption and diffusion experiments, these plates were positioned in reaction vessels containing $200 \mathrm{ml}$ of water, ethanol, or acetone. The temperature of the reaction vessels has been controlled through a temperature-controlled water bath. Afterwards, each specimen was dried carefully dabbing the wet surfaces with a wad of lint-free cotton wool and then reimmersed into the reaction vessel. It should be noted that the measuring time was kept below $30 \mathrm{~s}$ to keep evaporation processes at a minimum. Moreover, weights were measured using an analytical balance of a type Sartorius A200S (Göttingen, Germany; resolution: $0.1 \mathrm{mg}$ ). The weight gain during sorption experiments is described as the solvent mole uptake by $m_{\mathrm{p}}=100 \mathrm{~g}$ of polymer:

$$
c_{t}=\frac{m_{\mathrm{s}}}{\left(M_{\mathrm{s}}\right) \times\left(m_{\mathrm{p}}\right)} \times 100 \% \text {, }
$$

where $m_{\mathrm{s}}$ is the mass of sorbed solvent and $M_{\mathrm{s}}$ is its molar mass and $m_{\mathrm{p}}$ denotes the mass of the polymer.

2.4. Thermorheological Characterization. Using rectangular samples with dimensions of $\mathrm{W} \times \mathrm{H} \times \mathrm{L}: 2 \times 10 \times 50 \mathrm{~mm}^{3}$, dynamic mechanical thermal analysis (DMTA) experiments were accomplished in torsion mode with a stress-controlled rheometer with integrated Peltier-based temperature chamber (Anton Paar Physica MCR 301 plus CTD 180, Graz, Austria). During the torsion DMTA tests, a small uniaxial tensile force of around $0.5 \mathrm{~N}$ is superimposed to maintain the specimen under net tension. Thereupon, harmonic twist rotations with prescribed amplitude $(0.01 \%)$ and constant frequency of $10 \mathrm{~Hz}$ were executed while the samples were heated in predefined temperature intervals at a constant heating rate of $0.25^{\circ} \mathrm{C} / \mathrm{min}$ and the resulting harmonic 


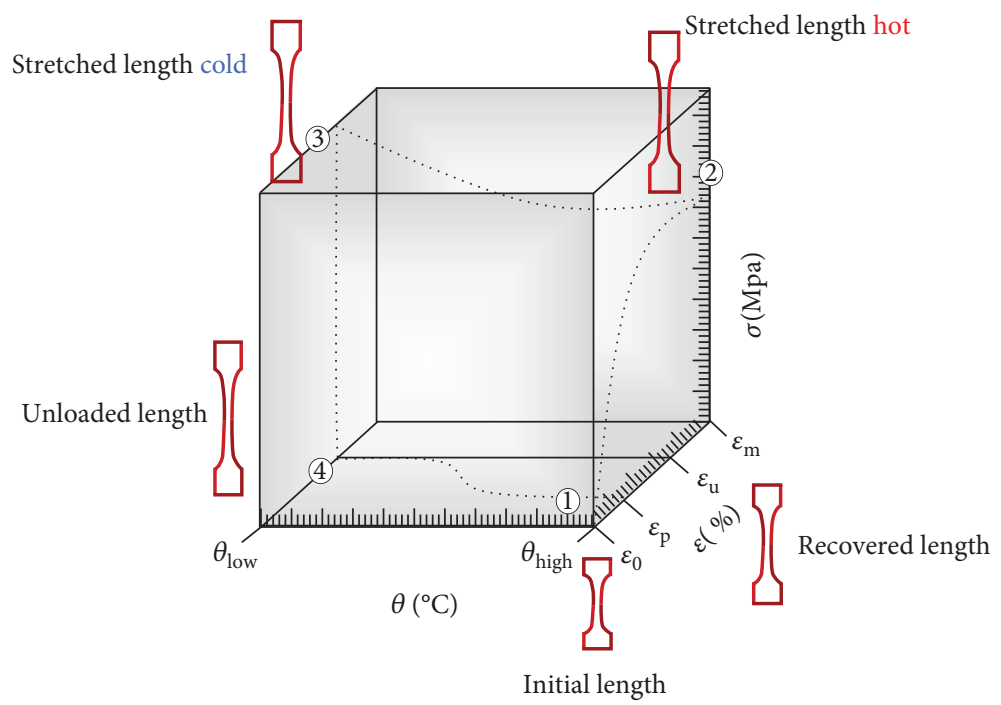

FIGURE 2: Schematic representation of a cyclic uniaxial thermomechanical tensile test in the $\sigma-\theta-\varepsilon$ diagram.

torque as well as the phase lag $\phi$ or loss factor $\tan \phi$ was measured. Such temperature sweep experiments provide important insights into the effective viscoelastic properties of the investigated material [27]. Here, the characteristic material properties like $\theta_{\mathrm{g}}$ can be determined through the sample's response to the applied periodic loadings. Again here, the experiments have been repeated two more times and the results originate from an average out of all three runs.

2.5. Cyclic, Thermomechanical Tensile Tests. For tensile tests, Estane sheets were punched to dumbbell specimens of type $5 \mathrm{~A}$ of DIN EN ISO $527-2\left(\mathrm{~W} \times \mathrm{H} \times \mathrm{L}: 2 \times 10 \times 75 \mathrm{~mm}^{3}\right)$. The gauge length of specimens is $25 \mathrm{~mm}$. Cyclic, thermomechanical tensile tests were performed on a spindle-driven testing machine (Schenck Trebel RM50, Germany) with an adjusted strain and compression capacity of $\pm 500 \mathrm{~N}$. The machine was equipped with a heating/cooling chamber (Fresenberger TK18.400.100, Wipperfürth, Germany). The temperature was PID-controlled (Eurotherm 3508, Limburg, Germany) so that temperatures in the range of -100 to $400^{\circ} \mathrm{C}$ could be adjusted and kept constant with a precision of $\pm 1^{\circ} \mathrm{C}$. Each cycle consisted of a SM creation procedure (SMCP) under strain-controlled modes and recovery modes. In the programming part, the samples were heated up from room temperature to the upper working temperature of $\theta_{\text {high }}=70^{\circ} \mathrm{C}$ with a moderated heating rate of $3^{\circ} \mathrm{C} / \mathrm{min}$. Following that, temperature $\theta_{\text {high }}$ was fixed and, in a strain-controlled mode, the samples were deformed up to the maximum uniaxial strain of $\varepsilon_{\mathrm{m}}$ at a rate of $0.0051 / \mathrm{s}$. Subsequently, the deformed specimens were kept constant at $\theta_{\text {high }}$ for different holding times $t_{\mathrm{h}}$. Under constant strain conditions, the specimens were then cooled down to a lower temperature of $\theta_{\text {low }}=10^{\circ}$ $\mathrm{C}$ with a cooling rate of $3^{\circ} \mathrm{C} / \mathrm{min}$ and equilibrated for $40 \mathrm{~min}$. Afterwards, the temporarily fixed strains $\varepsilon_{\mathrm{u}}$ were achieved along with the removal of stress. Under stress-free conditions, the recovery parts were induced by heat up of the programmed samples to $\theta_{\text {high }}=70^{\circ} \mathrm{C}$ with the same heating rate as mentioned before and equilibrated for $40 \mathrm{~min}$. Finally, the shape fixity and shape recovery ratios were measured for the quantification of the SME. Figure 2 demonstrates all steps of the thermomechanical tensile test cycle in a stress-temperature-stain $(\sigma-\theta-\varepsilon)$ diagram. These five steps of a cyclic uniaxial thermomechanical tensile test are based on strain-controlled programming and a stress-free recovery procedure. It should be noted that the thermomechanical tensile test was repeated once more $(N=2)$. However, only the results of the second cycle have been used for data interpretation, as the first cycle was utilized to erase the history of the system [28]. The results for the first cycle can be found in Supplement I. The following 2nd cycle could allow two different strain regimes with respect to the previous cycle $(N=1)$ in which the samples were stretched in a strain-controlled setting up to the maximum strain $\varepsilon_{\mathrm{m}}$. In subsequent thermomechanical tensile tests $(N>1)$, the sample in a strain-controlled process can be stretched up to the previous maximum strain $\varepsilon_{\mathrm{m} 2}=$ $\varepsilon_{\mathrm{m} 1}-\varepsilon_{\mathrm{u} 2}$, which is called strain length approach. Comparatively, it can be stretched with additional previous maximum strains $\varepsilon_{\mathrm{m} 2}=\varepsilon_{\mathrm{m} 1}$. This approach is called subsequent additional strain [29]. In this contribution, samples have been stretched in the second cycle up to $\varepsilon_{\mathrm{m} 2}$ according to strain length approach. These experiments have also been performed three times, and the results descend from the average out of them.

For the quantification of the SME of polymer samples, the shape fixity ratio $R_{\mathrm{f}}(N)$ and shape recovery ratio $R_{\mathrm{r}}(N)$ have been determined as important functional properties of the system. The shape fixity ratio $R_{\mathrm{f}}(N)$ is the ratio of the strain in a stress-free state after removing the tensile stress in the $N^{\text {th }}$ cycle $\varepsilon_{\mathrm{u}}(N)$ and the maximum strain $\varepsilon_{\mathrm{m}}(N)$. The shape recovery ratio $R_{\mathrm{r}}(N)$ is on the other hand the ratio between the remaining strain after the $N$ th cycle to the remaining strain in the previous cycle and can be determined from strain values according to 


$$
\begin{aligned}
& R_{\mathrm{f}}=\frac{\varepsilon_{\mathrm{u}}(N)}{\varepsilon_{\mathrm{m}}} \times 100 \%, \\
& R_{\mathrm{r}}=\frac{\varepsilon_{\mathrm{m}}-\varepsilon_{\mathrm{p}}(N)}{\varepsilon_{\mathrm{m}}-\varepsilon_{\mathrm{p}}(N-1)} \times 100 \% .
\end{aligned}
$$

Here, $\varepsilon_{\mathrm{p}}(N)$ is the recovered strain of the sample at the end of the recovery step.

2.6. Study of Diffusion Behavior. If the mode of diffusion is of Fickian type, then the diffusion rates of small molecules are faster than the relaxation process of polymer chains [30]. According to Fick's 1st law, moisture sorption occurs only by diffusion and the diffusion flux $\mathbf{j}(\mathbf{x}, t)$ is directly proportional to the gradient of its concentration:

$$
\mathbf{j}=-D \operatorname{grad} c,
$$

where $c(\mathbf{x}, t)$ is the sorbent concentration with units $\mathrm{mol} / \mathrm{m}^{3}$ and $D$ is the (isotropic) diffusion coefficient or diffusivity of a homogenous sample with units of $\mathrm{m}^{2} / \mathrm{s}$. The process of diffusion into the sample has therefore the following form:

$$
\begin{array}{r}
\operatorname{div} \mathbf{j}+\alpha \frac{\partial c}{\partial t}=0 \\
\alpha \frac{\partial c}{\partial t}-D \operatorname{div}(\operatorname{grad} c)=0 .
\end{array}
$$

To determine the changes of concentration of sorbents inside the sample at each point and time, (6) should be solved with respect to boundary conditions:

$$
\begin{aligned}
c & =\bar{c}, \quad \forall \bar{c} \in \Gamma_{D} \times t, \\
\mathbf{j} \cdot \mathbf{n} & =\bar{j}, \quad \forall \bar{j} \in \Gamma_{N} \times t,
\end{aligned}
$$

at the Neumann boundary $\Gamma_{N}$ and the Dirichlet boundary $\Gamma_{D}$ and initial conditions in the sample's domain $\Omega$ at $t=t_{0}$ :

$$
c=c_{0}, \quad \forall c_{0} \in \Omega \times t_{0} .
$$

Multiplying diffusion Equation (6) with a test function $\left(\delta_{c}\right)$ and integrating by parts over the domain of the sample leads to the weak form:

$$
\int_{\Omega} \alpha \partial_{t}(c) \delta c d V+\int_{\Omega}[D \operatorname{grad} c \cdot \operatorname{grad} \delta c] d V=\int_{\Gamma_{N}} \bar{j} \delta c
$$

Equation (9) is discretized with standard (Lagrangian) finite elements in the spatial domain. Applying an implicit backward Euler time stepping scheme, it could be solved numerically and the evolution of concentration $c(\mathbf{x}, \mathrm{t})$ can be analyzed for different sample geometries. Here, we investigate the mentioned samples of dimensions $\mathrm{W} \times \mathrm{H} \times \mathrm{L}$ : $2 \times 10 \times 50 \mathrm{~mm}^{3}$. The temporal concentration changes of the center of the mass of the sample have been recorded for three different probe molecules: acetone, ethanol, and water.

In addition to sorption, permeability is also important. The transport of small molecules inside polymers occurs through a solution-diffusion mechanism. This means that small molecules are first sorbed by the sample and then diffused inside it. The total amount of diffusion depends

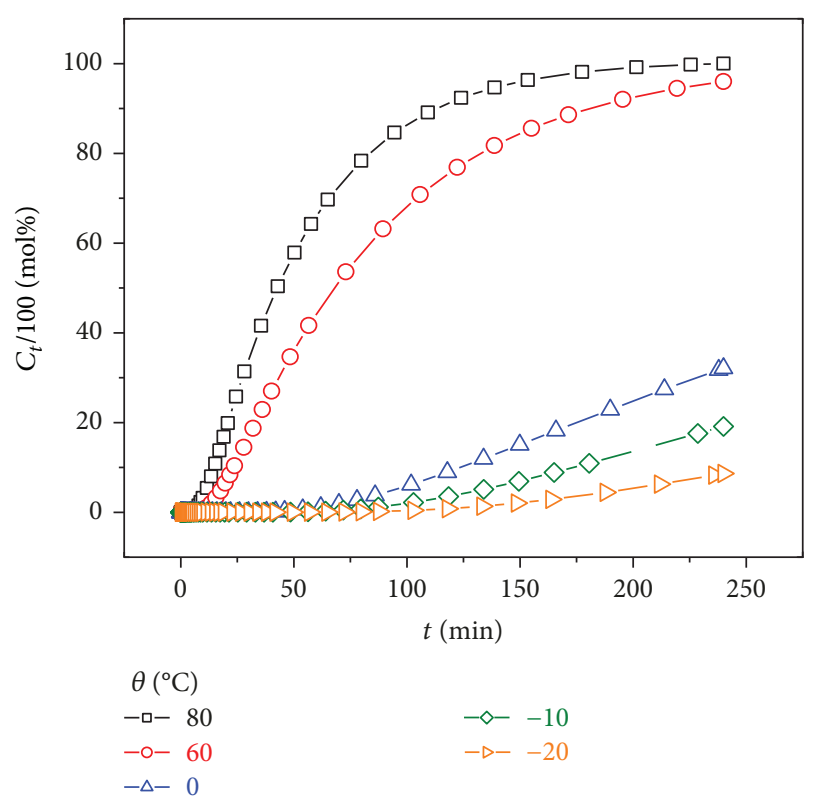

FIGURE 3: Simulation results for the temporal development of the changes in concentration of acetone in the middle of Estane samples with rectangular shapes $\left(\mathrm{W} \times \mathrm{H} \times \mathrm{L}: 2 \times 10 \times 50 \mathrm{~mm}^{3}\right)$ at different temperatures.

upon the existing number of probe molecules between two successive layers. For this reason, isotropic permeability $\zeta$ is introduced as

$$
\zeta=D S
$$

where $S$ is the solubility parameter with the unit of pascal ${ }^{1 / 2}$.

In addition to numerical solution of diffusivity, the diffusion coefficient $D$ can be calculated by a 1-dimensional analytical solution after an appropriate mathematical computation. A well-known analytical solution of $c(x)$ for a 1dimensional boundary value problem solution is developed by Crank [31], which is the most suitable for moderate and long-term experiments. More details about the numerical solution of Fick's law can be found in Supplement I Section S2.

\section{Results and Discussions}

3.1. Diffusion Behavior of Small Molecules into Estane Samples. The Fickian conduct of acetone, ethanol, and water inside Estane is studied at different temperatures experimentally and by the mean of finite element simulations. Since the qualitative behavior of the diffusion processes of the mentioned solvents into Estane is similar, only the results for acetone are shown here.

The simulation results for the temporal evolution of the concentration of acetone in the middle of the sample $\left(\mathrm{W} \times \mathrm{H} \times \mathrm{L}: 2 \times 10 \times 50 \mathrm{~mm}^{3}\right)$ for different temperatures modeled are shown in Figure 3. As can be recognized from this picture, the amount of acetone molecules which are diffused inside the sample, increases with temperature and the concentration profile has a biphasic form. Below $\theta_{\mathrm{g}}$, 


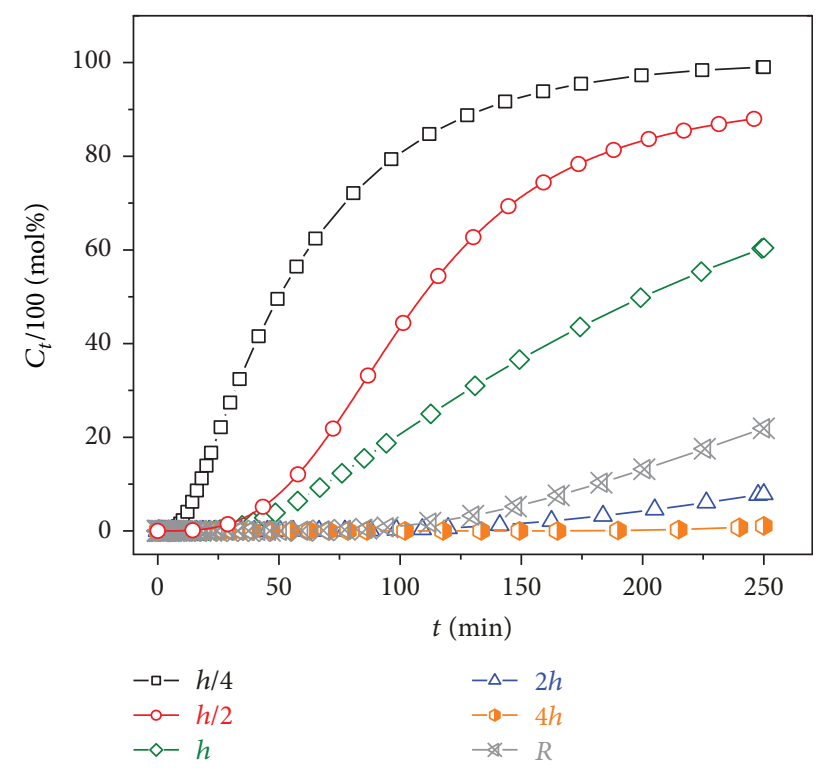

FIGURE 4: Simulation results of the influence of sample geometry on the amount of sorbed acetone at $\theta=20^{\circ} \mathrm{C}$. Rectangular samples have the dimension: $\mathrm{W} \times \mathrm{H} \times \mathrm{L}: 2 \times x \times 50 \mathrm{~mm}^{3}$, where $x$ changes from $h / 4$ to $4 h$ and $h$ is equal to $10 \mathrm{~mm}$. Cylindrical sample is $2 \mathrm{~mm}$ thick and has a radius of $R=h \mathrm{~mm}$.

the increase of acetone concentration is clearly lower than that of above $\theta_{\mathrm{g}}$ and a maximum amount of about $30 \%$ could be achieved at $\theta=0^{\circ} \mathrm{C}$. Moreover, as reported in [30], isothermal short-time and long-time experiments lead to similar data, meaning that the diffusion of all three small molecules in Estane shows no significant concentration dependency. However, once the $\theta_{\mathrm{g}}$ of the polymer is exceeded, the higher number of molecules is diffused as a result of activation volume according to Eyring's theory [32], so that after 175 minutes, the sample is totally saturated at $\theta_{\mathrm{g}}=80^{\circ} \mathrm{C}$. With an increase in temperature, the tortuous route of small penetrants decreases and the system reaches its equilibrium.

Another interesting parameter influencing the saturation time of the sample is the geometry as depicted in Figure 4. Here, at $\theta=20^{\circ} \mathrm{C}$, the simulation results for temporal changes of acetone concentration in the middle of rectangular and round disk Estane samples have been illustrated for different dimensions. As anticipated, samples with smaller widths are saturated faster than others. Intriguingly, in contrast to the first example, cylindrical specimens with the radius: $R=h$, are saturated faster than the sample with $W=2 h$.

The results of the diffusion coefficients for the sorption of acetone, ethanol, and water into Estane at three different temperatures are summarized in Table 1, respectively. It can be concluded from this table that the diffusivity shows no systematic dependence on the size of probe molecule, as acetone is the biggest and water is the smallest molecule in this study (Figure 5). This is because of the fact that the molecular mobility does not depend on the probe size.

More important is the correlation between the boiling point of the molecules and their evaporation energies. Molecules with higher boiling points and evaporation energies
TABle 1: Diffusion coefficient $(D)$ for sorption of acetone, ethanol, and water into Estane samples at three different temperatures $(\theta)$.

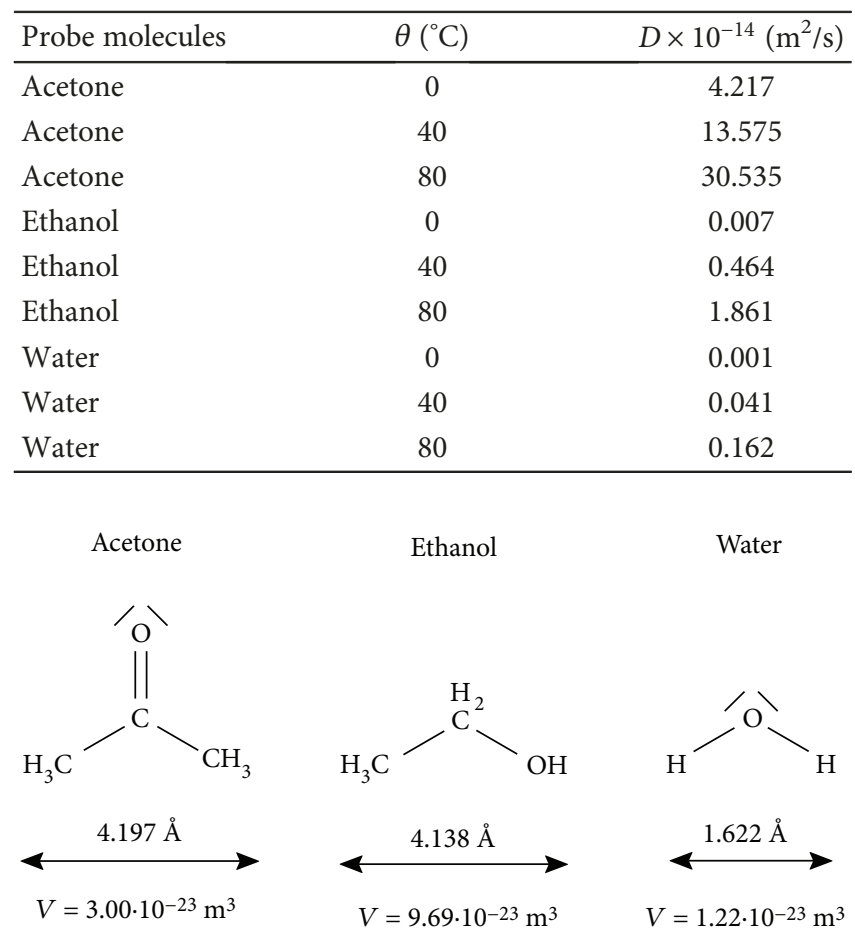

FIGURE 5: Structure formula and size of acetone, ethanol, and water, considering a spherical model [33]. The volume of the solvents and their radiuses are calculated from their densities at $\theta=20^{\circ} \mathrm{C}[34,35]$.

have smaller diffusion coefficients [35]. Sun and Chen [36] could achieve comparable results about the independence of the size of substituted probe molecules on the sorption and the diffusion processes into polyurethane/polymethyl methacrylate samples.

While the diffusivity of acetone at $-10^{\circ} \mathrm{C}$, that of ethanol at $19^{\circ} \mathrm{C}$, and that of water at $91^{\circ} \mathrm{C}$ are equal, the amount of solvent uptake inside the Estane is different as shown in Figure 6. As previously mentioned, here, other parameters like solubility play important roles. Therefore, as can be concluded from the offset of Figure 6, at the beginning, acetone is diffused faster into Estane and then water and finally ethanol. However, after $150 \mathrm{~min}$, ethanol diffuses clearly faster than others and a higher amount could be achieved.

As explained before, the dependency of the diffusion rate and the permeation upon temperature in sorption and desorption processes are evident [37]. To evaluate the activation energy of diffusion, its temperature dependency should be evaluated using the Arrhenius law.

$$
D=D_{0} \exp \left[-\frac{E_{\mathrm{a}}}{R \theta}\right]
$$

Here, $E_{\mathrm{a}}$ is the activation energy, $\theta$ the absolute temperature, and $R$ the universal gas constant equal to $8.314 \mathrm{~J} / \mathrm{mol} \cdot \mathrm{K}$.

Figure 7 shows the plot of $\ln (D)$ versus $\theta$ for three studied solvents. As the graph implies, an almost linear dependency can be observed for Estane solvent samples during this temperature range. The values of activation energy for 


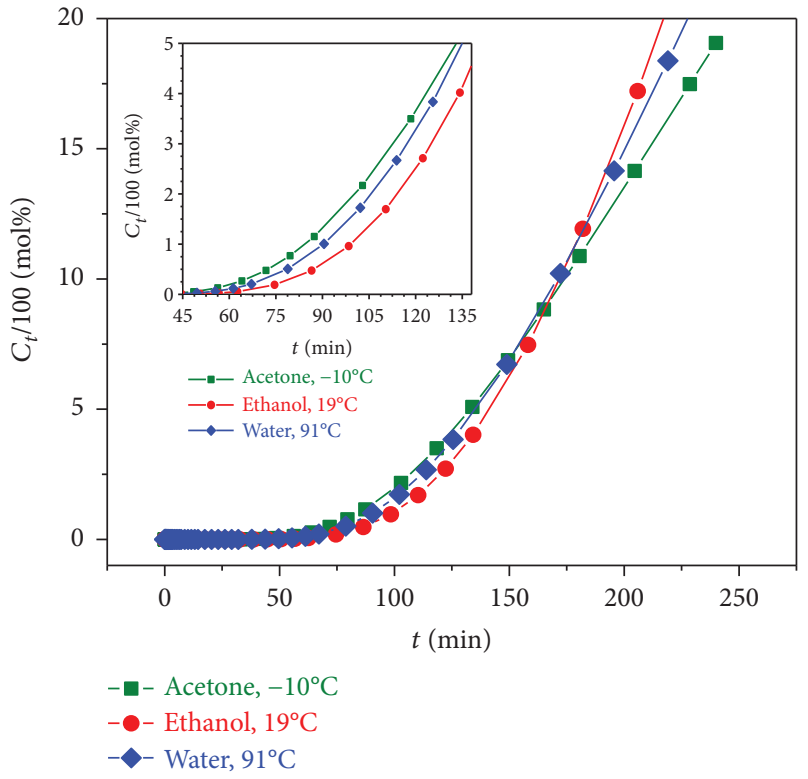

FIGURE 6: Simulation results of the temporal development of the concentration of acetone, ethanol, and water inside the rectangular sample $\left(\mathrm{W} \times \mathrm{H} \times \mathrm{L}: 2 \times 10 \times 50 \mathrm{~mm}^{3}\right)$ at $\theta=-10,19$, and $91^{\circ} \mathrm{C}$, respectively.

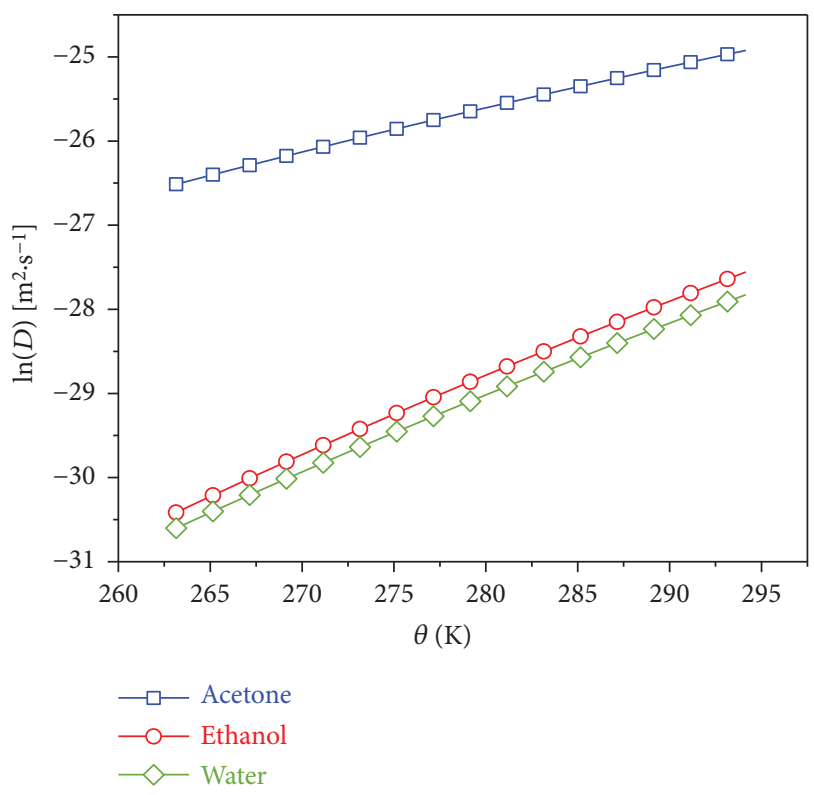

Figure 7: The temperature dependency of diffusion coefficients of three different solvents (acetone, ethanol, and water) inside Estane to demonstrate the dependence of $\ln (D)$ versus $\theta$ for the sorption process. The data are obtained from experimental weight gain measurements.

diffusion $\left(E_{0}\right)$ can be simply calculated using regression analysis from plots depicted in Figure 7. The apparent activation energies of acetone, ethanol, and water read 32, 58.3, and $56.5 \mathrm{~kJ} / \mathrm{mol}$, respectively. These results are in good agreement with activation energies of the same small molecules in similar polyurethanes [30].
TABLE 2: Solubility parameter of Estane, acetone, ethanol, and water as a summation of square Hildebrand and Scott components $\delta_{\mathrm{d}}, \delta_{\mathrm{p}}$, and $\delta_{\mathrm{h}}$. Data from the handbook of Hansen solubility parameters [38].

\begin{tabular}{lc}
\hline Sample & Solubility parameter $\delta\left((\mathrm{MPa})^{-0.5}\right)$ \\
\hline Generic polyurethane & 42 \\
Acetone & 33 \\
Ethanol & 44 \\
Water & 73 \\
\hline
\end{tabular}

In addition to diffusivity, the cohesive energy density (CED) and Hildebrand's solubility parameter can be used to calculate the permeability of the sorbents in polymer samples [38]. Hildebrand's solubility parameter $\delta=\sqrt{\mathrm{CED}}$ is a numerical estimation to indicate the strength of the molecular interaction between solvents and polymers. Materials with the same solubility parameter incline to dissolve in each other. The CED can be understood as the total amount of energy needed to completely remove a unit material volume from its neighbors to infinite separation. This value can be calculated in, for example, MD simulations as an increase in energy per mole material when all intermolecular forces have vanished [20]. The calculated solubility parameters of a representative polyurethane similar to Estane and three solvents are summarized in Table 2 . In this contribution, the derivation of cohesive energy density is based on three solubility parameters which have been first introduced by Hildebrand and Scott [38]. Here, it is assumed that the square root of cohesive energy density is a summation of three contributions: dispersion interaction $\delta_{\mathrm{d}}$, representing the van der Waals type of nonpolar attractive interactions, the $\delta_{\mathrm{p}}$ for interactions between permanent molecular dipoles, and the $\delta_{\mathrm{h}}$ representing a hydrogen type of bonding (H-bonds), which in Hansen's approach not only addresses interactions related to $\mathrm{H}$-bonds but also integrates other interactions.

It is clear that the solubility of polyurethane in water is weak and in acetone or ethanol clearly better, indicating that the affinity of polyurethane (Estane) is more toward ethanol or acetone. Moreover, the permeability and solubility parameters are in the same order.

Finally, the thermodynamic parameters for diffusion can be calculated using van't Hoff's relation [39]:

$$
\log K_{\mathrm{s}}=\left(\frac{\Delta S}{2.303 R}\right)-\left(\frac{\Delta H}{2.303 R \theta}\right) .
$$

Here, $(\Delta H)$ and $(\Delta S)$ are the values of change in enthalpy and entropy, respectively, and $K_{\mathrm{s}}$ is the equilibrium sorption constant, which can be estimated from the following equation:

$$
K_{\mathrm{s}}=\frac{n_{\mathrm{s}}^{\mathrm{eq}}}{m_{\mathrm{p}}}
$$

where $n_{s}^{\mathrm{eq}}$ denotes the number of moles of the sorbed solvent at the equilibrium. The values of $\Delta H$ and $\Delta S$ are listed in Table 3. These values were calculated from the slope and intercept of the plot of $\ln (K)$ versus $(1 / \theta)$. As can be noticed 
TABLE 3: Thermodynamic parameters for sorption in Estane and studied solvents.

\begin{tabular}{lccc}
\hline $\begin{array}{l}\text { Thermodynamic } \\
\text { parameters }\end{array}$ & $\begin{array}{c}\text { Estane/ } \\
\text { acetone }\end{array}$ & $\begin{array}{c}\text { Estane/ } \\
\text { ethanol }\end{array}$ & $\begin{array}{c}\text { Estane/ } \\
\text { water }\end{array}$ \\
\hline$\Delta S(\mathrm{~kJ} / \mathrm{mol} / \mathrm{K})$ & $8.58 \times 10^{-3}$ & $4.84 \times 10^{-3}$ & $\approx 0$ \\
$\Delta H(\mathrm{~kJ} / \mathrm{mol})$ & 0.06 & 0.026 & $\approx 0$ \\
\hline
\end{tabular}

for sorption, the values of $\Delta H$ are for all positive sorbents and in the range of $0.0267-0.06 \mathrm{~kJ} / \mathrm{mol}$. These positive values of $\Delta H$ are an indication for endothermic sorption dominated by the Fickian mode as a result of new pore creation inside the sample.

\subsection{Determination of Functional Properties of Dry and} Hydrolytically Aged Estane. Now that the diffusion of small molecules into polymer matrices has been studied, one can investigate the influence of such low molecular weight compounds on the shape-memory properties of the mentioned polyether urethane samples. As outlined before, in this part, we only concentrate on the effects of physical (hydrolytical) aging on the functional properties of Estane and the influence of other solvents will be discussed in a separate contribution.

In order to be able to investigate the influence of physical aging on the functional properties of Estane, the $\theta_{\mathrm{g}}$ of both dry and physically (hydrolytically) aged samples should be first determined and compared.

For $\theta_{\mathrm{g}}$ determination of dry Estane, temperature sweep tests of DMTA experiments were performed. The measured storage shear modulus $\left(G^{\prime}\right)$ and loss shear modulus $\left(G^{\prime \prime}\right)$ for dry Estane are depicted together with the results for physically (hydrolytically) aged samples in Figure 8 . As can be observed from this picture, the storage modulus of dry samples starts gradually decreasing with temperature until the temperature reaches the $\theta_{\mathrm{g}}$ of Estane (around $54^{\circ} \mathrm{C}$ ), where because of morphological softening a rapid decrease in the stiffness can be recognized. The $G^{\prime \prime}$ on the other hand increases very slightly up to this temperature and sharply decreases from there on with increasing temperature.

On the other hand, the influence of hydrolytic aging on the $\theta_{\mathrm{g}}$ of Estane is evident. Polymer chains of dry samples are relaxed and in entangled conformation. After physical (hydrolytical) aging, which takes place through diffusion of water molecules, the relaxed polymeric chains are pulled apart from each other and chains experience an internal stress (residual stress) that is counteracted by the tendency of polymer chains to return back to their relaxed minimum energy state.

The amount of water uptake for Estane was characterized by mass gain experiments and was found to be around $3 \mathrm{wt} . \%$ to $3.1 \mathrm{wt} . \%$ at room temperature after one week being settled in a water bath. As can be observed from Figure 8, the mechanical properties of physically (hydrolytically) aged samples are different from that of dry ones. This polymer softening (plasticization) effect [40] can be understood as a consequence of a water-induced swelling effect [41] which results in an increase of free volume between polymer chain segments and therefore, in an increase of chain mobility, was approved also by atomistic simulation studies $[20,21]$. Moreover, the presented evolution of the loss factor depicted on the right-hand side of Figure 8 reveals that the incorporation of water and consequentially the plasticization effect result in a shift of $\theta_{\mathrm{g}}$ to lower values. From this result, such a shift towards lower $\theta$ values with $\theta_{\mathrm{g}}^{\text {wet }}=48^{\circ} \mathrm{C}$ becomes obvious. This result could be approved qualitatively by atomistic simulation studies as shown in Figure 9.

It can be observed that the $\theta_{\mathrm{g}}$ decreases with the number density of small particles, diffused into a polymer melt. This trend is in accordance with experimental results shown in Figure 8 , where the size of small molecules is smaller than the Kuhn length of the studied polymer. In this figure, $\theta_{\mathrm{g}, 0}$ stands for $\theta_{\mathrm{g}}$ of pure polymers with the same chain length and in the same pressure. The Kunh length is a theoretical concept, which relates the number of conceptual segments in a real polymer chain to the number of segments in an equivalent freely jointed chain model. Since our model chain is chosen to be freely jointed already from the setup, one finds that the Kuhn length is of the order of one bead size $\left(\sigma_{p p}\right)$. Therefore, when the size of small particles is smaller than the Kuhn length for polymers, it is observed that increasing the concentration of small particles leads to the reduction of $\theta_{\mathrm{g}}$ in both MD simulations and experimental works.

We are aware of the fact that real samples do always contain a distribution of chain lengths and that this may be important for the observed properties. However, in order to gain a first qualitative understanding and for the sake of simplicity, we first focused on a monodisperse system. As mentioned above, despite this simplicity, the model predicts a decrease of $\theta_{\mathrm{g}}$ upon adding small molecules which is qualitatively in line with experimental results on storage and loss moduli shown in Figure 8, where the temperature corresponding to the maximum of the loss factor is shifted to lower temperatures by adding small molecules (physically (hydrolytically) aged sample). As the next step, it would be indeed very interesting to account for the effect of polydispersity. In view of the computational challenge, we would like to postpone this task to a future work.

\subsection{Shape-Memory Properties}

3.3.1. Shape-Memory Response, Influence of Holding Time. The influence of holding time following the maximum strain of $\varepsilon_{\mathrm{m}}=30 \%$ on the SM performance of dry and physically (hydrolytically) aged samples was investigated. Here, dry and physically (hydrolytically) aged specimens have been programmed according to the description mentioned in Section 2.5 , which will be explained briefly here. Estane polymer samples were stretched uniaxially at $\theta_{\text {high }}=70^{\circ} \mathrm{C}$ during programming from the initially nonstretched extension $\varepsilon_{0}=0 \%$ to the maximum strain of $\varepsilon_{\mathrm{m}}=30 \%$ and held at this temperature for different holding times in the range of 6$6000 \mathrm{~s}$. Afterwards, the stretched samples were cooled down from $\theta_{\text {high }}$ to $\theta_{\text {low }}=10^{\circ} \mathrm{C}$, while the stress was kept constant 


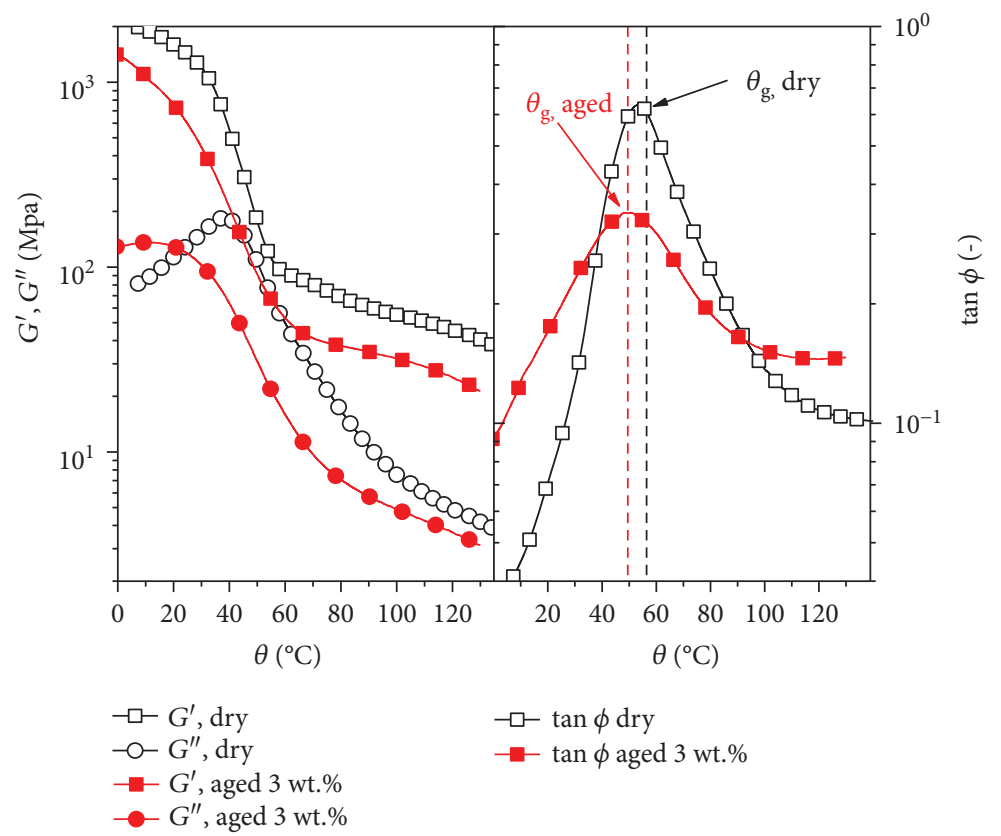

Figure 8: Comparison of the thermomechanical properties of dry (open symbols) and physically (hydrolytically) aged (solid symbols) Estane obtained from DMTA experiments. Left: changes of storage- $\left(G^{\prime}\right)$ and loss modulus $\left(G^{\prime \prime}\right)$ for dry (open symbols) and physically (hydrolytically) aged samples (solid symbols) in temperature sweep tests. Right: comparison of loss factor tan $(\phi)$ of dry (open symbols) and (hydrolytically) aged samples (solid symbols) [24].

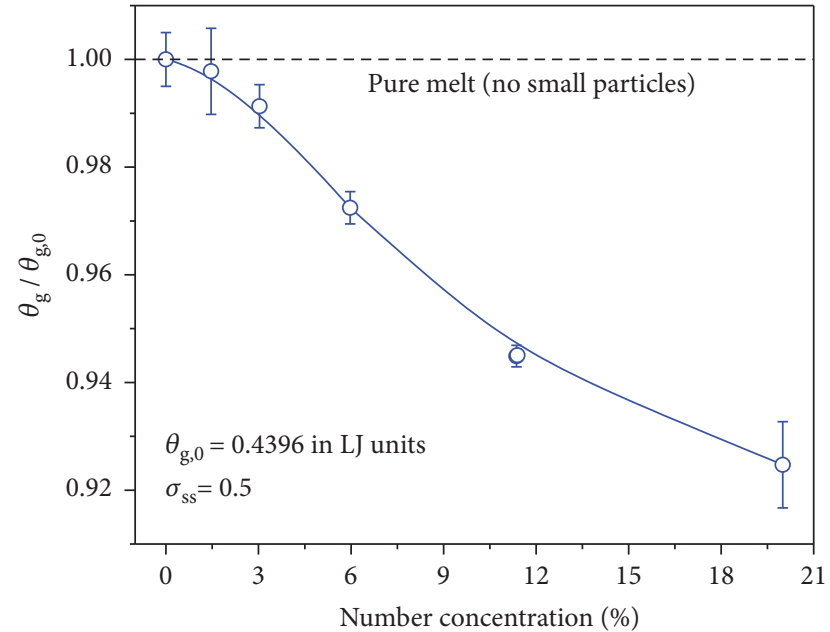

FIGURE 9: Results of MD simulations on $\theta_{\mathrm{g}}$ versus the concentration of small molecules, which diffuse into a polymer melt. The polymer melt is modelled here as a coarse-grained linear chain. The small molecules are spherical Lennard-Jones (LJ) particles. Despite the generic feature of the model, the qualitative trend observed here is in agreement with experiments [41]. Results from calculations performed on three independent packing models.

to solidify the oriented polymer chains. After cooling, the samples have been unloaded by releasing the stress and keeping them at $\theta_{\text {low }}$, which resulted in temporary fixed strain $\varepsilon_{\mathrm{u}}$. In the last step, under a stress-free condition, the samples have been brought to $\theta_{\text {high }}$, where the final recovered strains $\varepsilon_{\mathrm{p}}$ are achieved.
In Section S3 of Supplement I, Fig. S2 demonstrates the whole SM cycle in two subsequent runs in the stresstemperature-strain $(\sigma-\theta-\varepsilon)$ diagram for dry Estane stretched up to $\varepsilon_{\mathrm{m}}=30 \%$.

The evolution of normalized strain with time in recovery modulus for both samples together with the measured shape fixities as a function of time for different holding times $t_{\mathrm{h}}=6$, 60, 600, and $6000 \mathrm{~s}$ is depicted in Figure 10. Complementarily, the calculated shape fixities and shape recoveries for the second cycle are listed in Table 4. For comparison reasons, the results for the first cycle are summarized in Table S1 of Section S3 in Supplementary I. A thorough concerned description of results is also included.

As can be observed from Figures 10(a) and 10(b), the reduced strains $\left(\varepsilon / \varepsilon_{\mathrm{u}}\right)$ for both dry and physically (hydrolytically) aged samples during the recovery processes in the second thermomechanical cycle decrease with a sigmoidal function until it reaches the $\theta_{\mathrm{g}}$ of Estane. For dry samples, the rate of normalized strain began to slow down after $1500 \mathrm{~s}$. By relaxation times larger than $1500 \mathrm{~s}$, a steady normalized strain magnitude (equilibration) has been achieved. Figures 10(a) and 10(b) show that the increase in holding time has two effects on the functional properties of dry and physically (hydrolytically) aged specimens: it resulted in (1) a slower shape recovery rate and (2) a lower shape recovery ratio. Interestingly, obvious higher recovery ratios were obtained for physically (hydrolytically) aged samples. A possible reason for better functional properties of physically (hydrolytically) aged specimen could be presumed in the creation of additional physical crosslinks and different stabilizations of the polymer matrices through H-bond networks, which are created through absorbed water molecules. This 


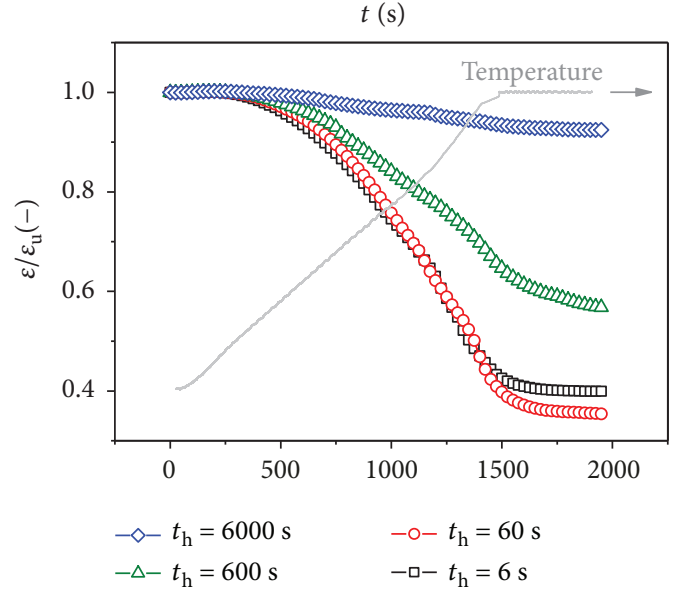

(a) Dry Estane

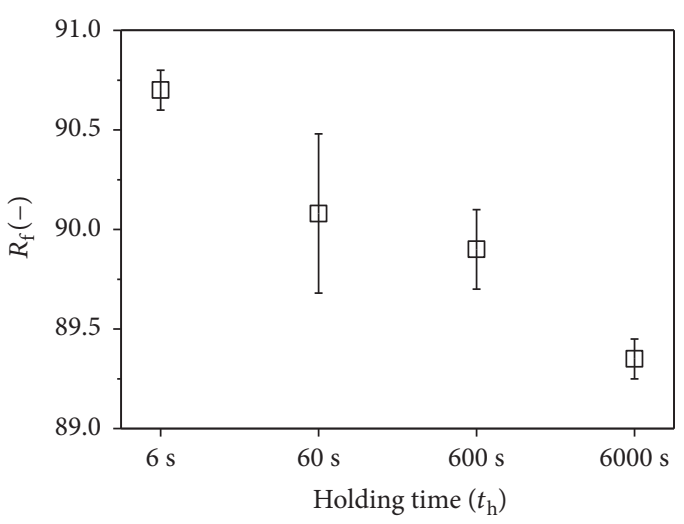

(c) $R_{\mathrm{f}}$ for dry Estane

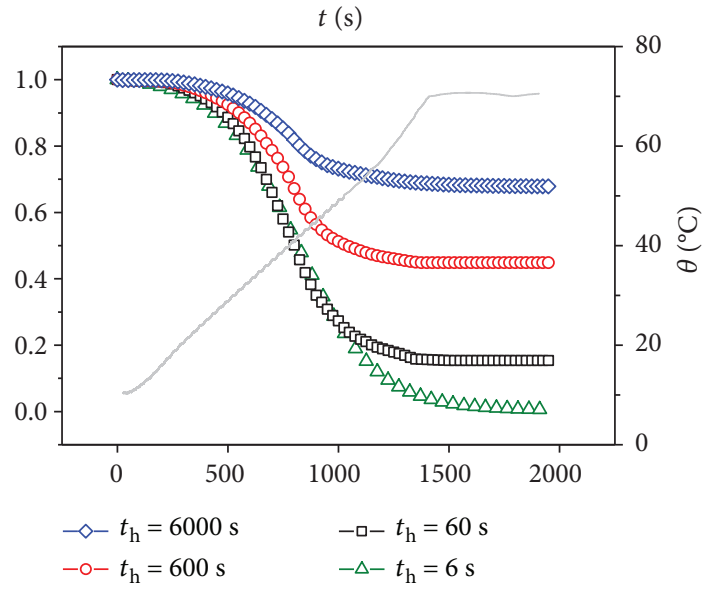

(b) Hydrolytically aged Estane

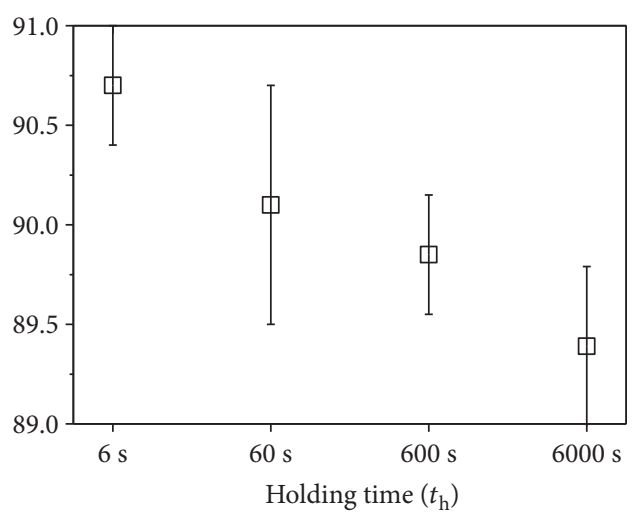

(d) $R_{\mathrm{f}}$ for hydrolytically aged Estane

FIGURE 10: Development of reduced strains of (a) dry- and (b) physically (hydrolytically) aged Estane samples with 3 wt.\% water during the recovery process in the 2 nd cycle with different holding times (from 6 to $6000 \mathrm{~s}$ ) after stretching up to $\varepsilon_{\mathrm{m}}=30 \%$ at $\theta_{\text {high }}=70^{\circ} \mathrm{C}$ in a cyclic thermomechanical tensile test. Achieved shape fixity ratio of (c) dry- and (d) physically (hydrolytically) aged Estane samples with 3 wt.\% water after two successive cycles. Results are the average of three similar test runs. The corresponding $\theta$ values are plotted as gray lines with respect to the right ordinate.

TABLE 4: Shape-memory properties of dry and physically (hydrolytically) aged Estane programmed at $\theta=70^{\circ} \mathrm{C}$. The results for the first cycle can be found in the Supplement I.

\begin{tabular}{lcc}
\hline Holding time $(\mathrm{s})$ & $R_{\mathrm{f}}(2)(\%)$ & $R_{\mathrm{r}}(2)(\%)$ \\
\hline & Dry samples \\
6 & $90.71 \pm 5.26$ & $65.00 \pm 7.01$ \\
60 & $90.11 \pm 5.00$ & $60.20 \pm 4.14$ \\
600 & $89.84 \pm 4.06$ & $43.71 \pm 4.23$ \\
6000 & $89.36 \pm 4.75$ & $8.00 \pm 3.37$ \\
\hline \multicolumn{3}{c}{} \\
6 & Physically (hydrolytically) \\
60 & aged samples \\
600 & $91.99 \pm 5.79$ \\
6000 & $92.15 \pm 5.97$ & $99.01 \pm 5.23$ \\
\hline
\end{tabular}

shows that even after heating processes during two cycles, the remaining water molecules participate in the recovery procedure and cause an improved shape recovery. The simulation results on SM properties of wet polyesters approve our results [42].

At elevated temperatures after deformation, if higher holding time is applied to the material, more time is given to the configurational changes to take place. This means that the material exhibits more resistance against locking in the strain and reasonably lower shape recovery. It was realized that there are chain regions in the molecular network of polymers which are normally inactive in quasistatic deformations but become stretched during fast deformations. The aforementioned regions have loose connectivity to the main load-bearing network and can reach a lower energy state when enough time is given. The relaxation process in polymers involves rapid readjustments of the kinks in local scales and slow rearrangement of the convolutions in longrange scales [43]. One presumption for this observation would be the chain alignment in the polymer matrices with time and consequently the increase in crystalline portions, which needs additional investigations through, for example, wide-angle X-ray scattering (WAXS) experiments [6]. Nevertheless, the number of crystalline portions of unstretched 


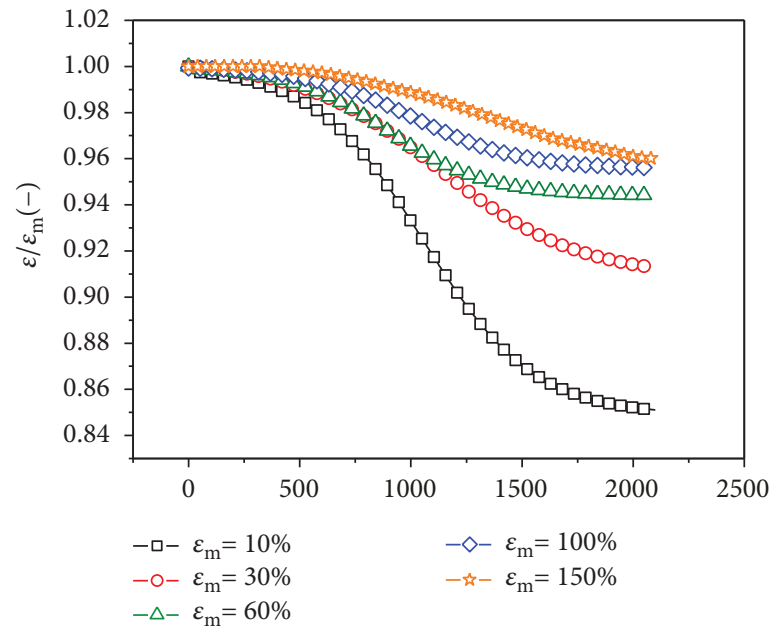

(a) Dry Estane

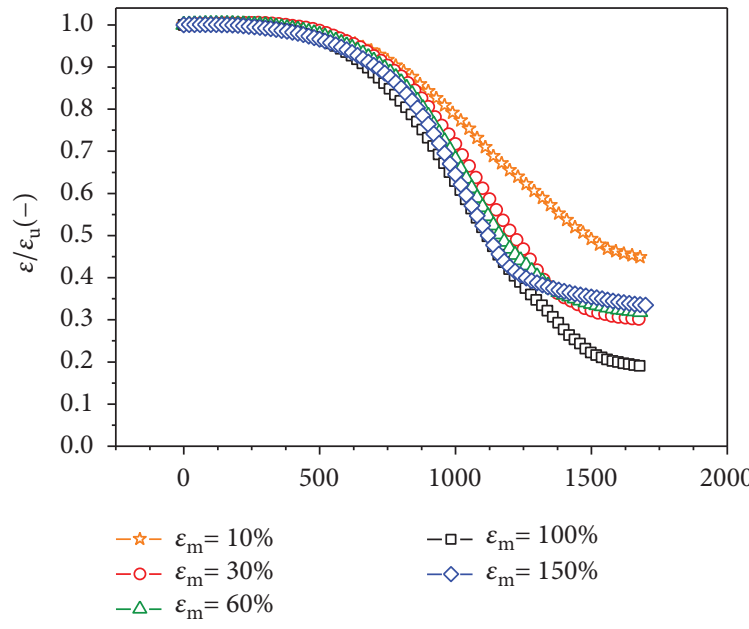

(c) Dry Estane

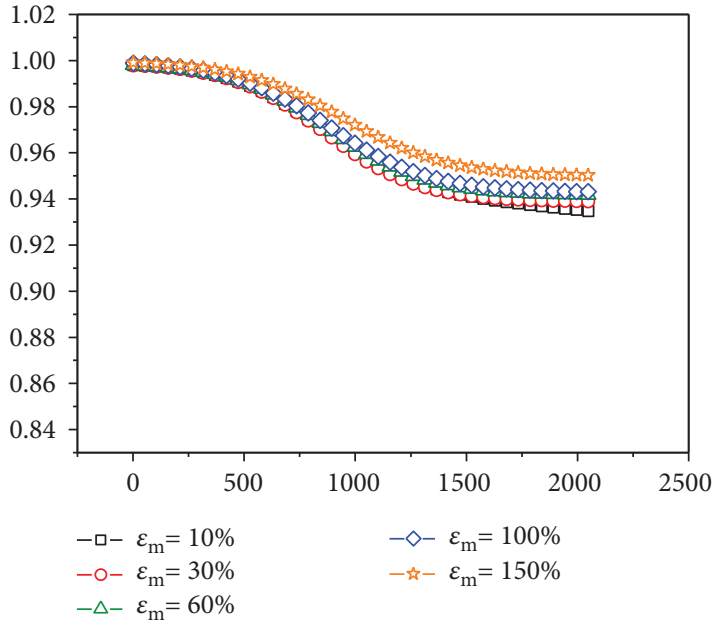

(b) Hydrolytically aged Estane

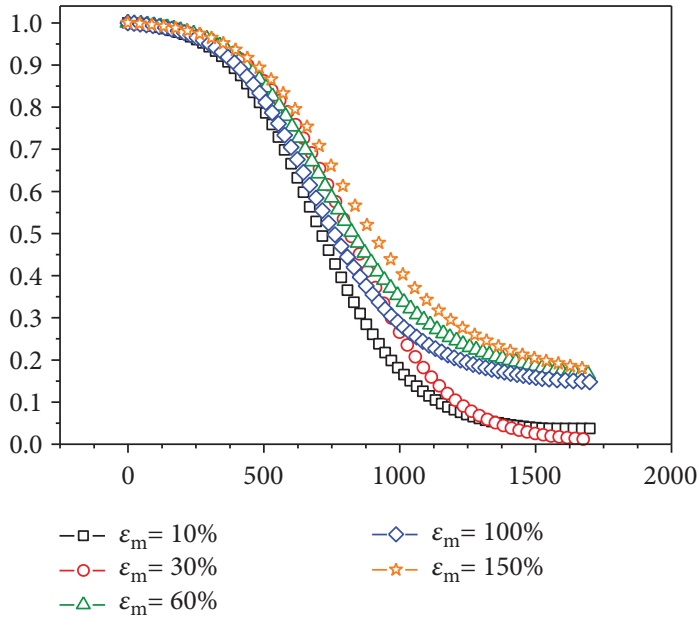

(d) Hydrolytically aged Estane

Figure 11: Development of reduced strain values $\left(\varepsilon / \varepsilon_{\mathrm{m}}\right)$ for (a) dry- and (b) physically (hydrolytically) aged Estane samples during the unloading process in the 2 nd cycle stretched up to different maximum strains $\varepsilon_{\mathrm{m}}$ (from $10 \%$ to $150 \%$ ) at $\theta_{\text {low }}=10^{\circ} \mathrm{C}$ in a cyclic thermomechanical tensile test. Development of reduced extension values $\left(\varepsilon / \varepsilon_{\mathrm{u}}\right)$ for $(\mathrm{c})$ dry- and (d) physically (hydrolytically) aged Estane samples during the recovery process in the 2 nd cycle stretched up to different maximum strains $\varepsilon_{\mathrm{m}}$ (from $10 \%$ to $150 \%$ ) at $\theta_{\text {high }}=70^{\circ} \mathrm{C}$ in a cyclic thermomechanical tensile test.

samples could be analyzed by differential scanning calorimetry (DSC) measurements. Such an experiment has been performed for dry Estane, and the results for two successive runs are depicted in Fig. S3 of Section S4 of Supplementary I.

The final achieved shape fixity ratios for both dry and physically (hydrolytically) aged samples are depicted in Figures 10 (c) and 10(d). It can be noticed that the shape fixity ratio of water swollen samples do not contradict with the $R_{\mathrm{f}}$ of the dry specimen between experimental errors. It is believed that at $\theta_{\text {low }}$ the mobility of chains and water molecules is so limited that no different shape fixation can be observed correspondingly. Moreover, it can be perceived that all samples showed good shape fixation in the range of 89$91 \%$, cf Table 4. Moreover, in the range of experimental errors, shape fixation does not change too much with increasing holding times for both dry and physically (hydrolytically) aged samples. In the literature, one finds different outcomes.
While in [44], it was demonstrated that an increase in holding time would improve the shape fixation; exactly the opposite case was reported in [45]. Therefore, it can be concluded that the holding time in stress-controlled experiments may affect the SM properties of the samples totally different [46].

\subsubsection{Shape-Memory Response, Influence of Maximum} Applied Strain. Another parameter influencing the functional properties and thermomechanical performance of SMPs is the final maximum strains during programming. Therefore, in the next step, dry and physically (hydrolytically) aged samples have been stretched during programming up to different final strains $\varepsilon_{\mathrm{m}}$ in the range of $10 \%$ to $150 \%$. It is noteworthy to mention that the holding time was $t_{\mathrm{h}}=6 \mathrm{~s}$ for all cycles.

Figure 11 shows the development of relative strain values of dry and physically (hydrolytically) aged polymer samples during unloading and recovery steps. The calculated shape 
TABLE 5: Shape-memory properties of dry and physically (hydrolytically) aged Estane programmed at $\theta=70^{\circ} \mathrm{C}$. The results for the first cycle can be found in Supplement I.

\begin{tabular}{|c|c|c|}
\hline Maximum strain $\varepsilon_{\mathrm{m}}(-)$ & $R_{\mathrm{f}}(2)(\%)$ & $R_{\mathrm{r}}(2)(\%)$ \\
\hline \multicolumn{3}{|c|}{ Dry samples } \\
\hline $10 \%$ & $85.07 \pm 3.44$ & $81.02 \pm 6.21$ \\
\hline $30 \%$ & $91.46 \pm 5.75$ & $71.11 \pm 6.94$ \\
\hline $60 \%$ & $94.47 \pm 5.39$ & $69.98 \pm 7.34$ \\
\hline $100 \%$ & $95.60 \pm 6.18$ & $67.18 \pm 8.56$ \\
\hline $150 \%$ & $95.84 \pm 4.28$ & $56.14 \pm 6.33$ \\
\hline \multicolumn{3}{|c|}{ Physically aged samples } \\
\hline $10 \%$ & $93.41 \pm 4.25$ & $99.03 \pm 3.67$ \\
\hline $30 \%$ & $91.99 \pm 5.79$ & $95.24 \pm 5.23$ \\
\hline $60 \%$ & $93.90 \pm 5.43$ & $88.20 \pm 4.97$ \\
\hline $100 \%$ & $94.65 \pm 7.63$ & $87.52 \pm 6.12$ \\
\hline $150 \%$ & $95.60 \pm 6.18$ & $84.33 \pm 6.18$ \\
\hline
\end{tabular}

fixities and shape recoveries of the samples for the second cycle are summarized in Table 5. Again, corresponding supportive results for the first runs can be found in Table S2 of Section S3 of Supplementary I.

As can be observed from Figures 11(a) and 11(b), the different applied maximum strains influenced the shape fixity process of both dry and physically (hydrolytically) aged samples at $\theta_{\text {low }}=10^{\circ} \mathrm{C}$. This shows that at $\theta_{\text {low }}$ polymer samples exhibited elastic response to the applied stretching, but the least part of elongation recovers right after unloading. Although reorientation of polymer chains at this temperature is hard, by increasing final elongations, the amount of unrecoverable strains seems to raise with $\varepsilon_{\mathrm{m}}$.

The relative strain values $\varepsilon / \varepsilon_{\mathrm{m}}$ presented in Figures 11(a) and 11(b) can be understood as the development of the apparent shape fixity ratio $R_{\mathrm{f} \text {,app }}$ during unloading at $\theta_{\text {low }}=$ $10^{\circ} \mathrm{C}$. After a time period of approx. $30 \mathrm{~min}$, the decay in $\varepsilon / \varepsilon_{\mathrm{m}}$ is almost completed for dry samples and a plateau value in the range of $R_{\mathrm{f} \text {,app }}=85 \%-96 \%$ was reached. In comparison, the shape fixation of physically (hydrolytically) aged samples approaches the plateau domain in less time. For physically (hydrolytically) aged Estane, the apparent shape fixity ratio is distinctly higher and in the range of $R_{\text {f,app }}=$ 93\%-96\%. As depicted in Figures 11(a) and 11(b), a rise in $\varepsilon_{\mathrm{m}}$ resulted in an increase of $R_{\mathrm{f}, \text { app }}$ from $85 \%$ for $\varepsilon_{\mathrm{m}}=10 \%$ to $96 \%$ for $\varepsilon_{\mathrm{m}}=150 \%$ for dry samples and an increase from $93 \%$ for $\varepsilon_{\mathrm{m}}=10 \%$ to $96 \%$ for $\varepsilon_{\mathrm{m}}=150 \%$ for physically (hydrolytically) aged samples.

The development of averaged strain values in relative units $\varepsilon / \varepsilon_{\mathrm{u}}$ for both dry and physically (hydrolytically) aged specimens is illustrated in Figures 11(c) and 11(d). Both dry and physically (hydrolytically) aged Estane showed qualitatively similar recovery behavior, whereby a plateau value could be attained for times larger than $t>30 \mathrm{~min}$. For the recovery step, the normalized representation of $\varepsilon / \varepsilon_{\mathrm{u}}$ as a function of time shows an obvious dependency on the maximum strains ( $\mathrm{cf}$ Table 5). It can be revealed that with increasing maximum strains $\varepsilon_{\mathrm{m}}$, the shape recoverability

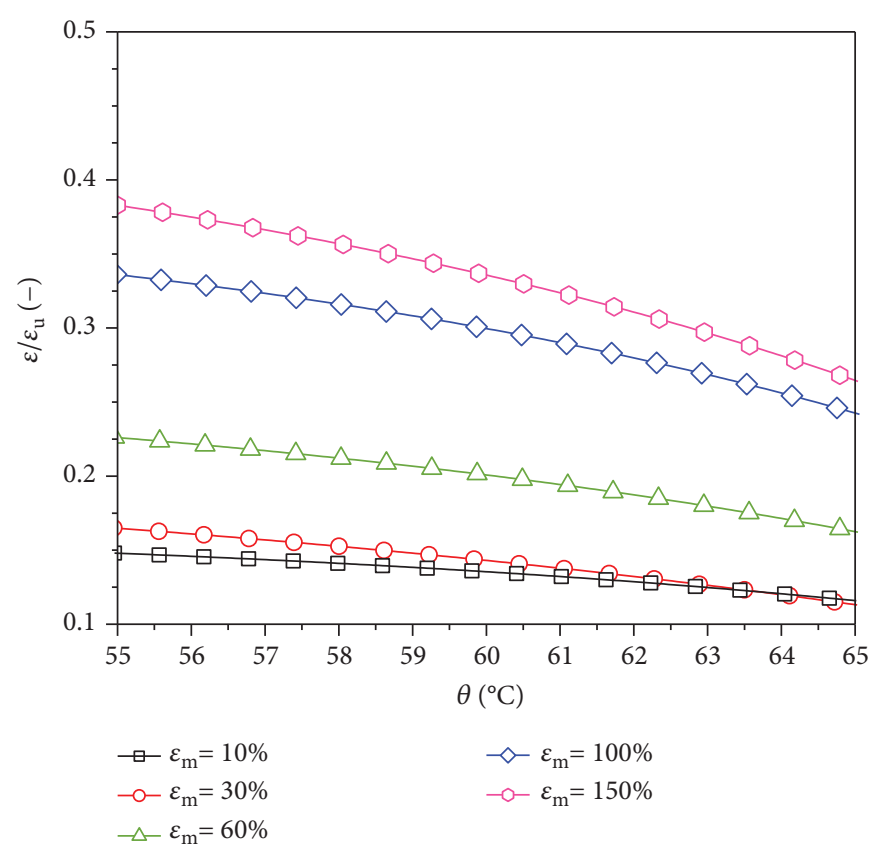

Figure 12: Development of reduced $\varepsilon$ values for dry Estane during the recovery process in the 2 nd cycle stretched up to different maximum strains $\varepsilon_{\mathrm{m}}$ (from $10 \%$ to $150 \%$ ) at $\theta_{\text {high }}=70^{\circ} \mathrm{C}$ in a cyclic thermomechanical tensile test.

$R_{\mathrm{r}}$ of both samples decreased from $81 \%$ to $56 \%$ for dry and from $99 \%$ to $84 \%$ in the case of physically (hydrolytically) aged samples.

It can be observed that the shape recovery effect decreases because of an increase in the amount of nonrecoverable (plastic) parts of the shape changes with an increase in $\varepsilon_{\mathrm{m}}$. This could be a consequence of oriented crystalline structures [47-49]. The observed decrease in recovery effects with an increasing final maximum strain has also been reported for other SMPs [50, 51].

Maximum final elongations do not only affect the shape recovery values but also influence the shape recovery rate of the samples. In Figure 12, the development of reduced strain values $\varepsilon / \varepsilon_{\mathrm{u}}$ for dry Estane in the recovery step is depicted as a function of temperature in the range of $55-65^{\circ} \mathrm{C}$. As can be indicated from Figure 12, the lower the strains $\varepsilon$ are, the faster is the recovery around $\theta_{\mathrm{g}}$. This finding might be interesting for applications, where faster recovery is demanded.

\section{Conclusion}

In the present contribution, we first studied the transport behavior of three substituted compounds (acetone, ethanol, and water) through Estane experimentally and with numerical simulations. It was revealed that even after 1 week, putting the samples in the corresponding solvent bathes, neither enthalpy relaxation nor monomer release, could occur because of the lack of hydrophilic groups. Moreover, it was demonstrated that the $\theta_{\mathrm{g}}$ lowering of physically aged samples was due to the plasticization effects and a consequence of higher capability of low molecular weight compounds and 
oriented polymer chains for molecular movements in a low energetic state. The increase in the interaction of water molecules with polar chain groups leads to disrupting the weak molecular interactions of adjacent polymer chains. This could be approved by atomistic simulation studies that indicated a $\theta_{\mathrm{g}}$-lowering of freely jointed polymer systems up to $7 \%$ for $12 \%$ number concentrations of spherical LennardJones (LJ) particles.

Moreover, the influence of physical (hydrolytical) aging, through the incorporation of 3 wt.\% water molecules into dry polymer matrices on the functional properties of the Estane, was studied. Dry and physically (hydrolytically) aged samples have been conducted to different maximum strains and different holding times. It could be indicated that the shape fixation of physically (hydrolytically) aged polymers do not differ from dry samples in the range of statistical errors. However, physical (hydrolytic) aging resulted in an obvious better and faster shape recovery ratio as a result of additional physical crosslinks.

We assume that the presented findings might motivate further knowledge-based researches for designing polymer systems with defined SM parameters.

\section{Disclosure}

The founding sponsors had no role in the design of the study; in the collection, analysis, or interpretation of data; in the writing of the manuscript; and in the decision to publish the results.

\section{Conflicts of Interest}

The authors declare no conflict of interest.

\section{Acknowledgments}

The authors are grateful to German Research Foundation for the financial support with the DFG Priority Program SPP 1713 "Chemomechanics" (Grant Project Number STE 969/8-1/8-2). The authors thank Sabine Ludwigs and Carsten Dingler (Institute of Polymer Chemistry, University of Stuttgart) for GPC experiment.

\section{Supplementary Materials}

As mentioned in the manuscript, some supporting information can be found in Supplement I. There, one can find the results of GPC experiments (Section S1). In addition to Section 2.6 and for the better understanding of the results, an analytical solution of diffusion for a 1-dimensional boundary value problem is discussed in Section S2 of Supplementary I. Moreover, in addition to Tables 3 and 4, first, a twosuccessive thermomechanical cycle for dry Estane stretched up to $\varepsilon_{\mathrm{m}}=30 \%$ is illustrated and briefly discussed demonstratively. Thereafter, the results of the first runs for the samples stretched up to different maximum strains and with different holding times are also summarized in Tables S1 and S2 of Supplementary I. At the end of Supplementary I Section S4, two runs of DSC are depicted and argued for dry Estane. (Supplementary Materials)

\section{References}

[1] M. Behl, M. Y. Razzaq, and A. Lendlein, "Multifunctional shape-memory polymers," Advanced Materials, vol. 22, no. 31, pp. 3388-3410, 2010.

[2] M. Behl, K. Kratz, J. Zotzmann, U. Nöchel, and A. Lendlein, "Reversible bidirectional shape-memory polymers," Advanced Materials, vol. 25, no. 32, pp. 4466-4469, 2013.

[3] J. Hu, Y. Zhu, H. Huang, and J. Lu, "Recent advances in shapememory polymers: structure, mechanism, functionality, modeling and applications," Progress in Polymer Science, vol. 37, no. 12, pp. 1720-1763, 2012.

[4] H. Meng and G. Li, "A review of stimuli-responsive shape memory polymer composites," Polymer, vol. 54, no. 9, pp. 2199-2221, 2013.

[5] M. Heuchel, T. Sauter, K. Kratz, and A. Lendlein, "Thermally induced shape-memory effects in polymers: quantification and related modeling approaches," Journal of Polymer Science Part B: Polymer Physics, vol. 51, no. 8, pp. 621-637, 2013.

[6] T. Sauter, M. Heuchel, K. Kratz, and A. Lendlein, "Quantifying the shape-memory effect of polymers by cyclic thermomechanical tests," Polymer Reviews, vol. 53, no. 1, pp. 6-40, 2013.

[7] T. D. Nguyen, C. M. Yakacki, P. D. Brahmbhatt, and M. L. Chambers, "Modeling the relaxation mechanisms of amorphous shape memory polymers," Advanced Materials, vol. 22, no. 31, pp. 3411-3423, 2010.

[8] J. Choi, A. M. Ortega, R. Xiao, C. M. Yakacki, and T. D. Nguyen, "Effect of physical aging on the shape-memory behavior of amorphous networks," Polymer, vol. 53, no. 12, pp. 2453-2464, 2012.

[9] T. Xie, K. A. Page, and S. A. Eastman, "Strain-based temperature memory effect for Nafion and its molecular origins," Advanced Functional Materials, vol. 21, no. 11, pp. 20572066, 2011.

[10] X. Gu and P. T. Mather, "Water-triggered shape memory of multiblock thermoplastic polyurethanes (TPUs)," RSC Advances, vol. 3, no. 36, pp. 15783-15791, 2013.

[11] B. Yang, W. M. Huang, C. Li, C. M. Lee, and L. Li, "On the effects of moisture in a polyurethane shape memory polymer," Smart Materials and Structures, vol. 13, no. 1, pp. 191-195, 2004.

[12] R. Xiao and T. D. Nguyen, "Modeling the solvent-induced shape-memory behavior of glassy polymers," Soft Matter, vol. 9, no. 39, pp. 9455-9464, 2013.

[13] T. Pretsch, I. Jakob, and W. Müller, "Hydrolytic degradation and functional stability of a segmented shape memory poly(ester urethane)," Polymer Degradation and Stability, vol. 94, no. 1, pp. 61-73, 2009.

[14] T. Pretsch, "Durability of a polymer with triple-shape properties," Polymer Degradation and Stability, vol. 95, no. 12, pp. 2515-2524, 2010.

[15] T. Xu and G. Li, "Durability of shape memory polymer based syntactic foam under accelerated hydrolytic ageing," Materials Science and Engineering: A, vol. 528, no. 24, pp. 7444-7450, 2011.

[16] B. F. Pierce, K. Bellin, M. Behl, and A. Lendlein, "Demonstrating the influence of water on shape-memory polymer networks based on poly[(rac-lactide)-co-glycolide] segments in vitro," The International Journal of Artificial Organs, vol. 34, no. 2, pp. 172-179, 2011. 
[17] W. M. Huang, B. Yang, L. An, C. Li, and Y. S. Chan, "Waterdriven programmable polyurethane shape memory polymer: demonstration and mechanism," Applied Physics Letters, vol. 86, no. 11, article 114105, 2005.

[18] G. Huang and H. Sun, "Effect of water absorption on the mechanical properties of glass/polyester composites," Materials \& Design, vol. 28, no. 5, pp. 1647-1650, 2007.

[19] Y. Chae Jung, H. Hwa So, and J. Whan Cho, "Waterresponsive shape memory polyurethane block copolymer modified with polyhedral oligomeric silsesquioxane," Journal of Macromolecular Science, Part B, vol. 45, no. 4, pp. 453461, 2006.

[20] E. Ghobadi, M. Heuchel, K. Kratz, and A. Lendlein, "Simulation of volumetric swelling of degradable poly[(rac-lactide)co-glycolide] based polyesterurethanes containing different urethane-linkers," Journal of Applied Biomaterials \& Functional Materials, vol. 10, no. 3, pp. 293-301, 2012.

[21] E. Ghobadi, M. Heuchel, K. Kratz, and A. Lendlein, "Atomistic simulation of the shape-memory effect in dry and water swollen poly[(rac-lactide)-co-glycolide] and copolyester urethanes thereof," Macromolecular Chemistry and Physics, vol. 215, no. 1, pp. 65-75, 2014.

[22] H. Lu, Y. Liu, J. Leng, and S. Du, "Qualitative separation of the physical swelling effect on the recovery behavior of shape memory polymer," European Polymer Journal, vol. 46, no. 9, pp. 1908-1914, 2010.

[23] E. Ghobadi, R. Sivanesapillai, J. Musialak, and H. Steeb, "Modeling based characterization of thermorheological properties of polyurethane ESTANE ${ }^{\mathrm{TM}}$," International Journal of Polymer Science, vol. 2016, Article ID 7514974, 11 pages, 2016.

[24] E. Ghobadi, M. Elsayed, R. Krause-Rehberg, and H. Steeb, "Demonstrating the influence of physical aging on the functional properties of shape-memory polymers," Polymers, vol. 10, no. 2, pp. 107-131, 2017.

[25] C. Schmidt, A. M. S. Chowdhury, K. Neuking, and G. Eggeler, "Studies on the cycling, processing and programming of an industrially applicable shape memory polymer Tecoflex ${ }^{\circledR}$ (or TFX EG 72D)," High Performance Polymers, vol. 23, no. 4, pp. 300-307, 2011.

[26] S. Plimpton and B. Hendrickson, "A new parallel method for molecular dynamics simulation of macromolecular systems," Journal of Computational Chemistry, vol. 17, no. 3, pp. 326337, 1996.

[27] E. Ghobadi, R. Sivanesapillai, J. Musialak, and H. Steeb, “ Thermo-rheological characterization of polyetherurethane: Parameter optimization and validation," Constitutive Models for Rubbers IX, vol. 1, pp. 157-163, 2015.

[28] E. Ghobadi, M. Heuchel, K. Kratz, and A. Lendlein, "Influence of different heating regimes on the shape-recovery behavior of poly(L-lactide) in simulated thermomechanical tests," Journal of Applied Biomaterials \& Functional Materials, vol. 10, no. 3, pp. 259-264, 2012.

[29] E. Ghobadi, M. Heuchel, K. Kratz, and A. Lendlein, "Simulating the shape-memory behavior of amorphous switching domains of poly(l-lactide) by molecular dynamics," Macromolecular Chemistry and Physics, vol. 214, no. 11, pp. 1273-1283, 2013.

[30] A. Marquardt, S. Mogharebi, K. Neuking, F. Varnik, and G. Eggeler, "Diffusion of small molecules in a shape memory polymer," Journal of Materials Science, vol. 51, no. 21, pp. 9792-9804, 2016.
[31] J. Crank, The Mathematics of Diffusion, Science Publications, Oxford, UK, 2nd edition, 1975.

[32] T. M. Aminabhavi and R. S. Khinnavar, "Diffusion and sorption of organic liquids through polymer membranes: 10. Polyurethane, nitrile-butadiene rubber and epichlorohydrin versus aliphatic alcohols $\left(\mathrm{C}_{1}-\mathrm{C}_{5}\right)$," Polymer, vol. 34 , no. 5, pp. 10061018, 1993.

[33] U. S. Aithal, T. M. Aminabhavi, and S. S. Shukla, "Diffusivity, permeability, and sorptivity of aliphatic alcohols through polyurethane membrane at 25,44, and 60 .degree.C," Journal of Chemical \& Engineering Data, vol. 35, no. 3, pp. 298-303, 1990.

[34] G. W. C. Hung and J. Autian, "Use of thermal gravimetric analysis in sorption studies II: evaluation of diffusivity and solubility of a series of aliphatic alcohols in polyurethan," Journal of Pharmaceutical Sciences, vol. 61, no. 7, pp. 10941098, 1972.

[35] H. Kumar and Siddaramaiah, "A study of sorption/desorption and diffusion of substituted aromatic probe molecules into semi interpenetrating polymer network of polyurethane/polymethyl methacrylate," Polymer, vol. 46, no. 18, pp. 7140-7155, 2005.

[36] Y. M. Sun and J. Chen, "Sorption/desorption properties of ethanol, toluene, and xylene in poly(dimethylsiloxane) membranes," Journal of Applied Polymer Science, vol. 51, no. 10, pp. 1797-1804, 1994.

[37] J. Burke, "Solubility parameters: theory and application," The American Institute for Conservation Annual, vol. 3, pp. 1358, 1984.

[38] C. M. Hansen, The three Dimensional Solubility Parameters and Solvent Diffusion Coefficient, Danish Technical Press, Copenhagen, Denmark, 1967.

[39] M. Karimi, "Diffusion in polymer solids and solutions," Mass Transfer in Chemical Engineering Processes, pp. 17-41, InTech, 2011.

[40] E. Muñoz and J. A. García-Manrique, "Water absorption behaviour and its effect on the mechanical properties of flax fibre reinforced bioepoxy composites," International Journal of Polymer Science, vol. 2015, Article ID 390275, 10 pages, 2015.

[41] E. Mahmoudinezhad, A. Marquardt, G. Eggeler, and F. Varnik, "Molecular dynamics simulations of entangled polymers: the effect of small molecules on the glass transition temperature," Procedia Computer Science, vol. 108, pp. 265-271, 2017.

[42] E. Ghobadi, M. Heuchel, K. Kratz, and A. Lendlein, "Influence of the addition of water to amorphous switching domains on the simulated shape-memory properties of poly(l-lactide)," Polymer, vol. 54, no. 16, pp. 4204-4211, 2013.

[43] H. Khajehsaeid, J. Arghavani, R. Naghdabadi, and S. Sohrabpour, "A visco-hyperelastic constitutive model for rubber-like materials: a rate-dependent relaxation time scheme," International Journal of Engineering Science, vol. 79, pp. 44$58,2014$.

[44] A. J. W. McClung, G. P. Tandon, and J. W. Baur, "Deformation rate-, hold time-, and cycle-dependent shape-memory performance of veriflex-e resin," Mechanics of TimeDependent Materials, vol. 17, no. 1, pp. 39-52, 2013.

[45] D. Santiago, F. Ferrando, and S. De la Flor, "Influence of holding time on shape recovery in a polyurethane shape-memory polymer," Journal of Materials Engineering and Performance, vol. 23, no. 7, pp. 2567-2573, 2014. 
[46] J. K. Lee, K. H. Lee, and B. S. Jin, "Structure development and biodegradability of uniaxially stretched poly(l-lactide)," European Polymer Journal, vol. 37, no. 5, pp. 907-914, 2001.

[47] Y. S. Wong, Z. H. Stachurski, and S. S. Venkatraman, "Orientation and structure development in poly(lactide) under uniaxial deformation," Acta Materialia, vol. 56, no. 18, pp. 5083-5090, 2008.

[48] Y. S. Wong and S. S. Venkatraman, "Recovery as a measure of oriented crystalline structure in poly(l-lactide) used as shape memory polymer," Acta Materialia, vol. 58, no. 1, pp. 49-58, 2010.

[49] X. L. Lu, W. Cai, Z. Gao, and W. J. Tang, "Shape memory effects of poly(L-lactide) and its copolymer with poly( $\varepsilon$-caprolactone)," Polymer Bulletin, vol. 58, no. 2, pp. 381-391, 2007.

[50] C. Schmidt, K. Neuking, and G. Eggeler, "Functional fatigue of shape-memory polymers," MRS Proceedings, vol. 1190, 2009.

[51] B. K. Kim, S. Y. Lee, and M. Xu, "Polyurethanes having shape memory effects," Polymer, vol. 37, no. 26, pp. 5781-5793, 1996. 


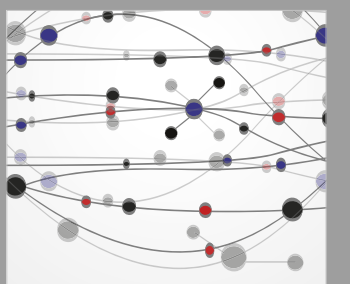

The Scientific World Journal
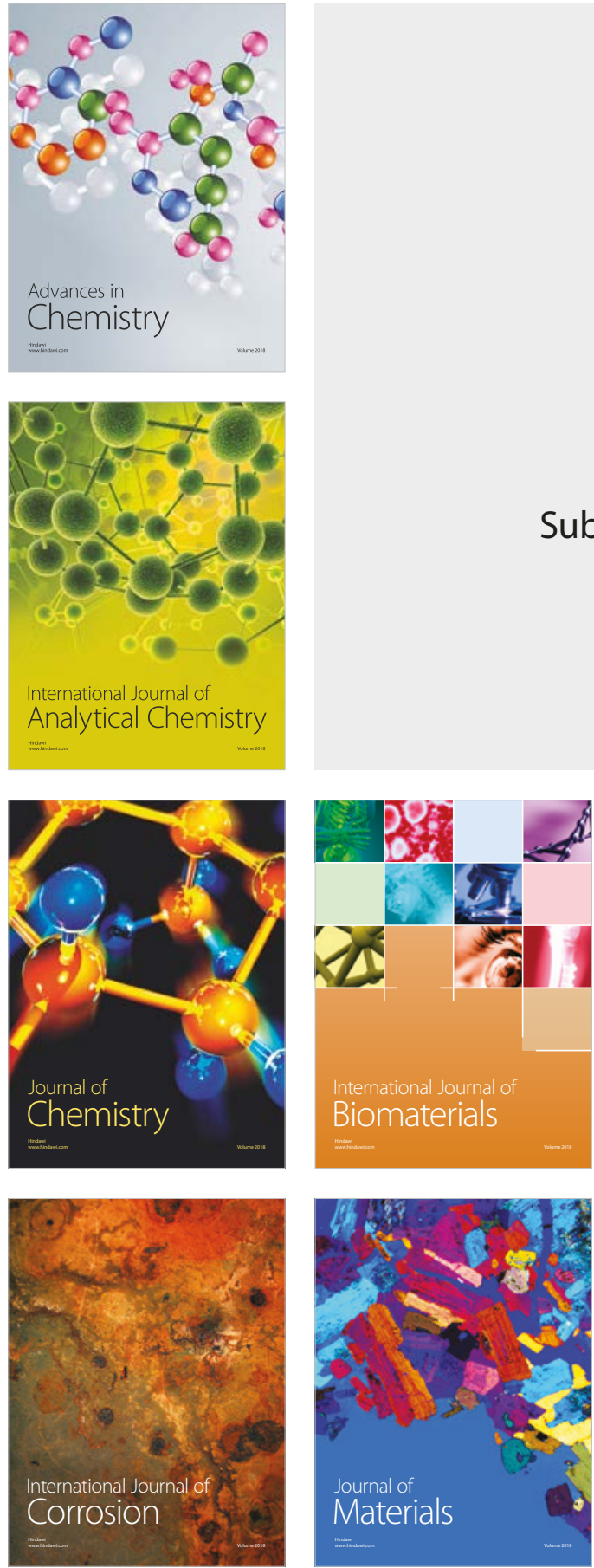

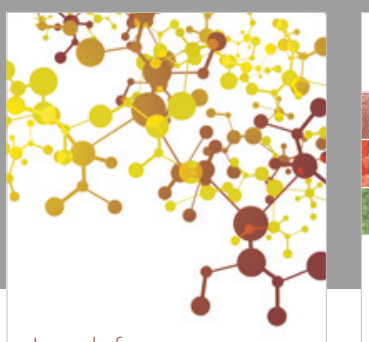

Journal of

Applied Chemistry
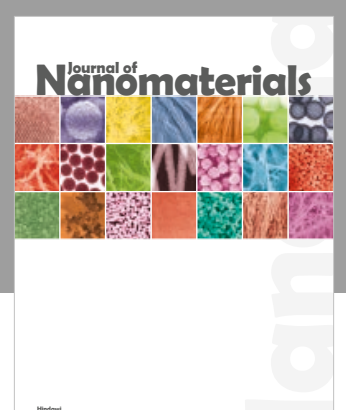

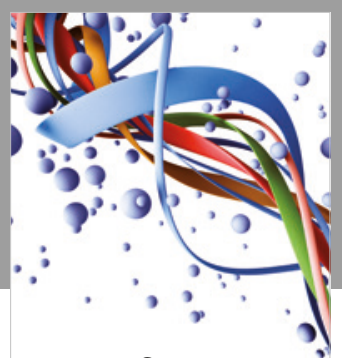

Scientifica

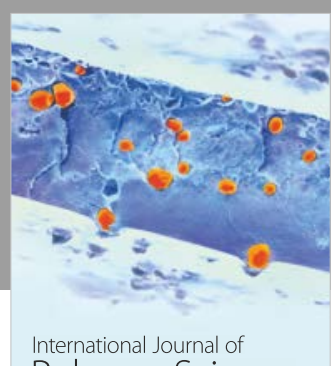

Polymer Science

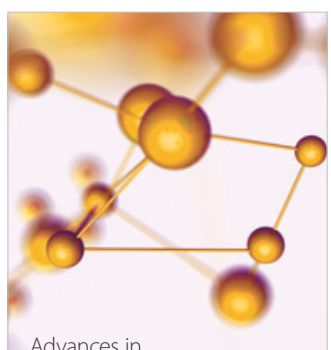

Physical Chemistry
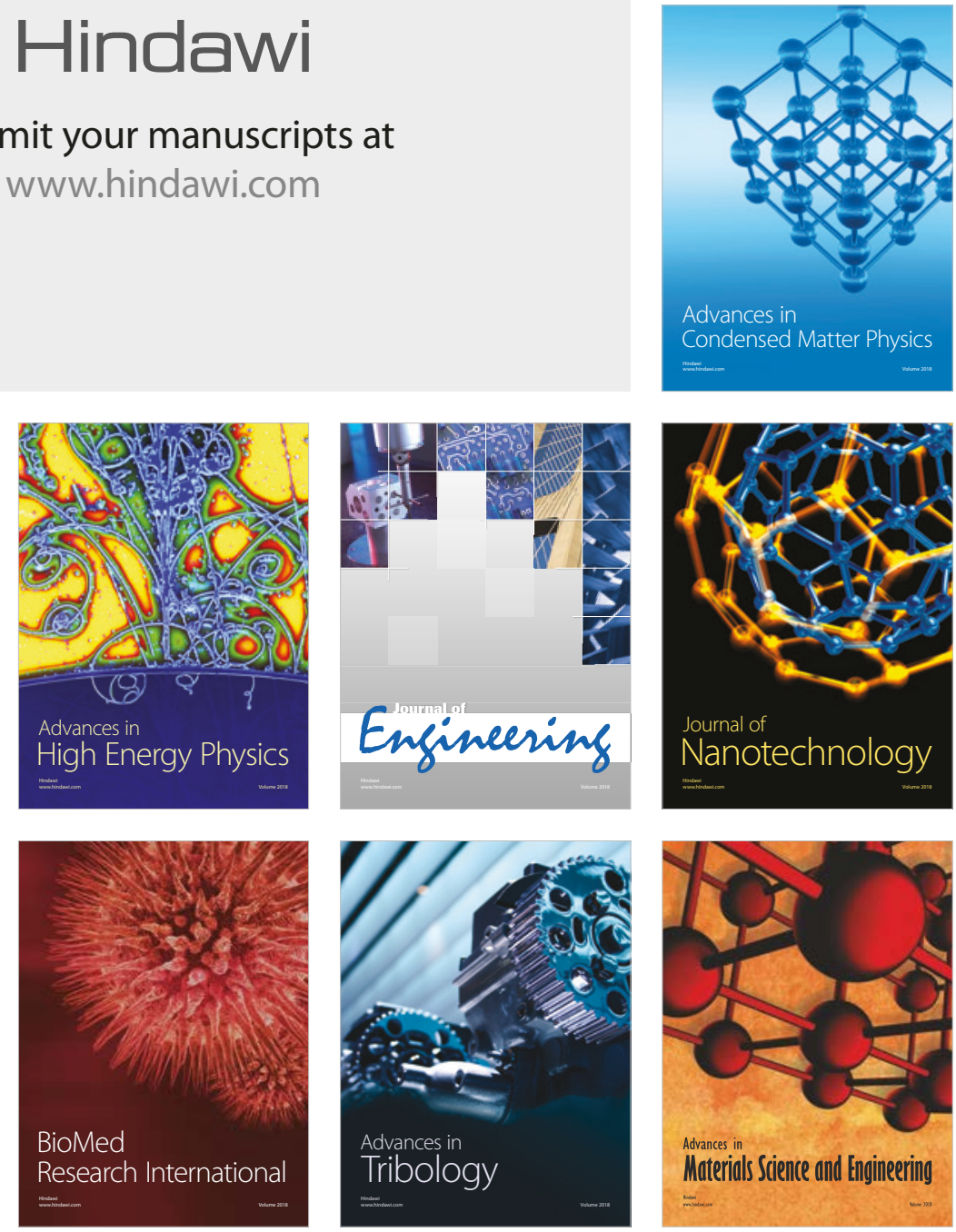